\title{
The Adipocyte as a Secretory Organ: Mechanisms of Vesicle Transport and Secretory Pathways
}

\author{
Richard L. Bradley, Kelly A. Cleveland, and Bentley Cheatham \\ Research Division, Joslin Diabetes Center and the Department of Medicine, \\ Harvard Medical School, Boston, Massachusetts 02215
}

\begin{abstract}
Obesity is a common problem in western society that is directly linked to several disease processes and is associated with significant morbidity and mortality. Adipocytes - the primary site for energy storage (as triglycerides) and release - were long suspected to have an active role in regulating body weight homeostasis and energy balance. As a result, many studies have focused on finding abnormalities in adipocyte physiology and metabolism. An cver-increasing body of cvidence indicates that, in addition to serving as a repository for energy reserves, adipocytes secrete a myriad of factors that comprise a complex network of endocrine, autocrine, and paracrine signals. Very little is known regarding the molecular mechanisms utilized by the adipocyte in regulating the biosynthesis and exocytosis of these secreted products. In order to gain a better understanding of these processes, we have examined the two classical secretory pathways: regulated and constitutive. Using leptin as a model adipocyte-secretory protein, this review focuses primarily on the latter pathway. This includes regulation of leptin synthesis and secretion by insulin and glucocorticoids and, more recently, the finding that the orexigenic neuropeptide, melanin-concentrating hormone $(\mathrm{MCH})$, can stimulate leptin synthesis and secretion. This chapter also incorporates new data describing the partial purification and effect of insulin on leptin-containing vesicles in rat adipocytes. These data indicate that the majority of leptin trafficking occurs via a constitutive secretory pathway and that the primary acute insulin effect on leptin secretion is to increase leptin protein content. In addition, we describe the identification and characterization of the vesicle-associated protein, pantophysin, which may play a multifunctional role in vesicle biogenesis and transport.
\end{abstract}

\section{Introduction}

The cloning of the $o b$ gene (Zhang et al., 1994) and the identification of its secreted product, leptin, as an adipocyte-derived hormone that communicates information regarding the size of adipose depots to the brain firmly established an active role for the adipocyte in regulating energy balance. These findings also triggered a renewed frenzy of research aimed at dissecting and analyzing the complex network of endocrine, paracrine, and autocrinc signals cmanating from adipocytes. Indeed, it has become increasingly apparent that the adipocyte functions as a global regulator of metabolic activity via this complex network. Adipocytes express and secrete a plethora of molecules, leptin being one of the morenotable ones. Two types of adipose tissue - white and brown - exist, each with 
distinct physiological roles. While there is evidence suggesting that brown adipose tissue (BAT) expresses some leptin (Frederich et al., 1995; Moinat et al., 1995; Deng et al, , 1997), the vast majority of leptin is synthesized and secreted by white adipose tissue (WAT). Furthermore, studies to date indicate that WAT is a primary source of key factors involved in the regulation of various cell biological processes. A summary of the various adipocyte secretory products is shown in Table I. The roles of many of these adipocyte-derived signals are still not fully understood. However, these proteins consist of a group of molecules that affect numerous cell biological and metabolic functions, such as glucose and lipid metabolism, insulin action, insulin secretion, energy balance, host defense, and reproduction. Hence, by virtue of the multitude of signals emanating from it, the adipocyte plays a critical role in regulating a multitude of biological processes. Furthermorc, it has become increasingly apparent that dysregulation of these signals in the obese state underlies the pathophysiology and sequelae of numerous diseases.

TABLE I

Known Adipocyte Secretory Proteins

- Leptin

- Alternative complement pathway proteins (adipsin, C3, B)

- Adipocyte complement related protein of $30 \mathrm{kDa}$ (ACRP30)

- Acylation-stimulating protein (ASP)

- Lipoprotein lipase (LPL)

- Nonesterified fatty acids (NEFAs)

- Cholesteryl ester transfer protein

- Apolipoprotein E (ApoE)

- Retinol-binding protein

- Vascular endothelial growth factor (VEGF)

- Monobutyrin

- Tumor necrosis factor-alpha (TNF- $\alpha)$

- Interleukin-6 (IL-6)

- Angiotensinogen

- Plasminogen activator inhibitor-1 (PAI-1)

- Transforming growth factor-beta (TGF- $\beta$ )

- Hepatocyte growth factor

- Insulin-like growth factor-1 (IGF-1)

- Adiponectin

[Data taken from Dobson, D., Kambc, A, Block, E., Dion, T., Lu, HI, Castellot, J., and Spiegelman, B. Cell 61, 223-230, 1990; Claffey, K.,Wilkison, W., and Spiegelman, B. J. Biol. Chem. 267, 16317-16322, 1992; Scherer, P., Williams, S., Fogliano, M., Baldini, G., and Lodish, H.F. J. Biol. Chem. 270, 26746-26749, 1995; Wei, S., Lai, K., Patel, S., Piantedosi, R., Shen, H., Colantuoni, V., Kraemer, F., and Blaner, W. J. Biol. Chem. 272, 14159-14165, 1997; Mohamed-Ali, V., Pinkney, J.H., and Coppack, S.W. Intl. J. Obesity Relat. Metab. Disord. 22, 1145-1158, 1998; Ouchi, N., Kihara, S., Arita, Y., Maeda, K., Kuriyama, H., Okamoto, Y., Hotta, K., Nishida, M., Takahashi, M., Nakamura, T., Yamashita, S., Funahashi, T., and Matsuzawa, Y. Circulation 100, 2473-2476, 1999.] 


\section{Functions of Adipocyte Secretory Products}

The exact roles of adipocyte-derived signals are not fully understood. Nonetheless, our current knowledge of the functions of these factors continues to expand rapidly. For example, leptin's ability to relay information regarding the size of adipose depots from the adipocyte to the brain is well established. However, the signaling pathways governing cross-talk between adipocytes and the brain are still not fully defined. In addition, the cytokines tumor necrosis factoralpha (TNF- $\alpha$ ) and interleukin-6 (IL-6) have important roles in host defense and may regulate both glucose and lipid metabolism (Castell et al., 1989; Grunfeld and Feingold, 1991). TNF- $\alpha$ also is reported to act as a mitogenic agent, to induce apoptosis of adipocytes, to stimulate leptin secretion, as well as to regulate mitochondrial function and gene expression (Prins et al., 1997). Acylation-stimulating protein (ASP) is involved in fatty acid metabolism, translocation of glucose transporters to the cell surface, as well as triglyceride synthesis and storage (Cianflone et al., 1992). Conversely, lipoprotein lipase (LPL) is known to be involved in the hydrolysis of triglycerides from circulating chylomicrons and very-low-density lipoproteins (Spooner et al., 1979). Cholesteryl ester transport protein facilitates uptake of cholesteryl esters from high-density lipoproteins into adipocytes (Benoist et al., 1998). Both vascular endothelial growth factor (VEGF) and monobutyrin have angiogenic effects in vivo and stimulate mitogenesis of vascular endothelial cells in vitro (Dobson et al., 1990; Claffey et al., 1992). Retinol-binding protein is a plasma transport protein for retinol (Wei et al., 1997), while angiotensinogen promotes adipocyte differentiation (Wciglc, 1997). Very recently, a new adipocyte secretory product, adiponectin, was reported (Ouchi et $a l ., 1999)$. Adiponectin is a plasma protein abundantly present in the systemic circulation. It apparently accumulates in vascular walls in response to endothelial injury and is thought to modulate the endothelial inflammatory response (Ouchi et al., 1999). These are only a few examples of the variety of signals governed by adipocyte-secretory products.

\section{Consequences of Obesity on Adipose Tissue Function}

Obesity is regarded as a pathological state that results in dysregulation of the endocrine function of adipose tissue. This dysfunction, in turn, can lead to numerous cardiovascular and metabolic disease processes, including hypertension, hyperlipidemia, hyperglucocorticoidemia, hyperinsulinemia, and type 2 diabetes. Obesity results in increased secretion of several adipocyte-derived factors (e.g., leptin, TNF- $\alpha$, IL-6, NEFA) (Mohamed-Ali et al., 1998). The initial effects of increased secretion of these factors serve to limit further weight gain by a variety of mechanisms, including 1) reduction of food intake, 2) increase in energy expenditure, 3) induction of insulin resistance, 4) stimulation of lipolysis, 5) 
suppression of lipogenesis, and 6) induction of adipocyte de-differentiation and reduction of preadipocyte differentiation (Prins et al., 1997; Mohamed-Ali et al., 1998). However, in an obese state, chronic exposure to elevated concentrations of these agents can have deleterious effects. For example, chronically elevated TNF$\alpha$ directly induces insulin resistance in both adipose tissue and skeletal muscle, which, in turn, can lead to type 2 diabetes and cardiovascular anomalies (Prins $e t$ al., 1997). Similarly, increased NEFA as a consequence of obesity may play a role in the pathogenesis of insulin resistance and hyperinsulinemia (Mohamed-Ali et al., 1998). Interestingly, adiponectin has been shown to inhibit TNF- $\alpha$-induced responses. Adiponectin levels are decreased in the obese state (Ouchi et al., 1999). Thus, obesity-induced decreases in adiponectin may further facilitate the adverse effects of TNF- $\alpha$ on various metabolic processes. In addition, decreased secretion of adiponectin in obesity has been linked to thrombotic vascular disease (Funahashi et al., 1999). Furthermore, plasminogen activator inhibitor-1 (PAI-1), which is overexpressed in obesity, may play a role in vascular disease (Funahashi $e t$ al., 1999), while increased IL-6 secretion in obesity may result in increased hepatic synthesis of pro-coagulant factors (Mohamed-Ali et al., 1998).

Despite the relatively large volume of secreted factors from adipocytes, the pathways and molecular components governing intracellular vesicular traffic and exocytosis of these factors remain relatively obscure. Like neuroendocrine cells, adipocytes have two primary secretory pathways: regulated and constitutive. This chapter will briefly discuss the components and current model for insulin-stimulated Glut 4 translocation as an example of a regulated pathway. As an example of a constitutive pathway, we will describe the regulation of leptin biosynthesis and secretion and its intracellular vesicle transport pathways. Furthermore, pantophysin was very recently identified as a phosphoprotein component of adipocyte transport vesicles and is present on both Glut4 vesicles and on a population of leptin-containing vesicles (Brooks et al., 2000). We will summarize the characterization of pantophysin and discuss the potential impact of these findings on the study of vesicle trafficking and secretion in adipocytes.

\section{Leptin and Signaling via the Leptin Receptor}

Many systematic studies on the pathophysiology of obesity have focused on mice homozygous for the obese $(o b)$ mutation. The $o b / o b$ mice display severe obesity and type 2 diabetes as well as a host of other metabolic and cardiovascular anomalies. Zhang et al. (1994) identified the gene responsible for the ob/ob mouse phenotype and its encoded protein, leptin, a 16-kDa protein secreted primarily by adipocytes. Numerous studies using a variety of rodent models have firmly established leptin as a key factor for regulating body weight and energy expenditure. Several excellent reviews on leptin and its role in regulating energy homeostasis 
are available (Caro et al., 1996; Auwerx and Staels, 1998; Trayhurn et al., 1999). The ability of leptin to regulate energy balance is based primarily on its capacity for relaying information regarding the size of adipose depots from the adipocyte to the brain. These effects of leptin are believed to be mediated through a closedloop feedback system involving the hypothalamus, within which leptin receptors have been identified (Mercer et al., 1996). In humans, however, the role of leptin in regulating adiposity appears to be more complex than in rodent models of obesity. Most obese individuals have higher levels of circulating leptin than their lean counterparts and appear to be resistant to their cndogenous leptin production. This observation has led to the "leptin resistance" hypothesis (Auwerx and Staels, 1998). A recent study showed that a leptin-inducible member of the suppression of cytokine signaling (SOCS) family, SOCS-3, inhibits leptin signaling in mammalian cell lines. It was proposed that SOCS-3 may be a potential mediator of leptin resistance in obesity (Bjorbaek et al., 1998). Overall, though, unlike in the $o b / o b$ mouse, human obesity is not a consequence of absolute leptin deficiency per se. Nonetheless, although cases are rare, deficiencies in leptin production and/or the leptin receptor have been linked to human obesity (Montague et al., 1997; Ravussin et al., 1997; Clement et al., 1998; Strobel et al., 1998).

Aside from regulating energy homeostasis, leptin is reported to have several other effects (Casanueva and Dieguez, 1999). Leptin is implicated in regulating fertility and is a permissive factor for the onset of puberty. The placenta is a source of leptin and leptin is present in human milk, suggesting that it may play a role in gestation and infant development. Furthermore, leptin is reported to have a role in hemopoiesis, to regulate cortisol secretion, and to facilitate activation and proliferation of human circulating $\mathrm{T}$ lymphocytes. Leptin is also involved in the neuroendocrine control of growth hormone secretion and there is some evidence that leptin may regulate thyrotropin-releasing hormone (TRH)-thyrotropin (TSH) and prolactin secretion (Casanueva and Dieguez, 1999).

In addition to being present in the hypothalamus, leptin receptors have been detected at lower amounts in several peripheral tissues, including heart, lung, liver, kidney, skeletal muscle, adipose tissue, and pancreatic $\beta$ cells (Tartaglia et al., 1995; Lee et al., 1996; Emilsson et al., 1997). This suggests that leptin signals to a variety of tissue and organ systems. The physiological significance of this expression, however, remains unclear. The leptin receptor gene is complex and encodes at least five different isoforms (Tartaglia et al., 1995; Lee et al., 1996). The "long-form" leptin receptor is considered the main signal-transducing form. It is abundantly expressed in the hypothalamus and, to a lesser extent in peripheral tissues, where the short form predominates (Lee et al., 1996; Tartaglia et al., 1995). The leptin receptor belongs to the class I cytokine receptor family (Tartaglia et al., 1995). Leptin receptor signaling is accomplished via the JAKSTAT pathway and involves transmission of the leptin signal via JAK-2 to STATs 
3, 5, and 6 (Baumann et al., 1996; Ghilardi et al., 1996; Vaisse et al., 1996). The leptin receptor is mutated in several rodent models of obesity, including the $d b / d b$ mouse, the Zucker fatty rat $(f a / f a)$, and the Koletsky rat (Auwerx and Staels, 1998). As previously mentioned, leptin receptors are present on pancreatic $\beta$ cells. Studies using both $o b / o b$ and wild-type mice have shown that leptin can effectively inhibit secretion of insulin (Emilsson et al., 1997; Kieffer et al., 1997), indicating that leptin may play a physiological role as an inhibitor of insulin secretion. The so-called adipoinsular axis postulates the existence of a feedback loop between adipose tissue and the endocrine pancreas (Kieffer et al., 1996). Furthermore, a number of studies have indicated a potential role for leptin in the pathogenesis of peripheral insulin resistance. It has been shown that both acute and chronic in vitro treatment of Hep G2 cells or rat fibroblasts with leptin caused attenuation of insulin-stimulated phosphorylation of insulin receptor substrate-1 (IRS-1). Exposure of primary rat adipocytes to leptin in vitro has been shown to decrease insulin-stimulated glucose metabolism (Cohen et al., 1996; Muller et al., 1997; Kroder et al., 1996).

\section{Regulation of Leptin Biosynthesis and Secretion}

In an effort to better understand secretory pathways utilized by the adipocyte, we have studied leptin secretion (and Glut4 translocation, to be discussed later in this chapter). Synthesis and secretion of leptin is regulated by a complex series of neuroendocrine, endocrine, and paracrine signals to which the adipocyte is exquisitely sensitive. The underlying biochemical and molecular mechanisms that regulate leptin synthesis and secretion are not fully defined. However, several positive and negative regulators of leptin production by adipocytes have been identified. Positive effectors include insulin, glucocorticoids, TNF- $\alpha$, prolactin, A1 adenosine receptor agonists, and estrogens (Mohamed-Ali et al., 1998; Casanueva and Dieguez, 1999; Gualillo et al., 1999; Rice et al., 2000). Conversely, negative regulators of leptin production include catecholamines, androgens, cAMP agonists, $\beta$-adrenergic receptor agonists, peroxisome proliferator-activated receptor gamma (PPAR- $\gamma$ ) agonists, phorbol esters, and possibly thyroid hormone (Mohamed-Ali et al., 1998; Casanueva and Dieguez, 1999). It is noteworthy that, depending on their location, adipose tissues respond differently to these agents. As examples, subcutaneous adipocytes apparently respond more to insulin and less to glucocorticoids than do omental adipocytes, while female adipose tissue responds more robustly to steroid hormones than does male adipose tissue (Casanueva and Dieguez, 1999). Many systematic studies of factors regulating leptin production by adipocytes have focused on two principal candidates, glucocorticoids and insulin. With rare exception (Rentsch and Chiesi, 1996), glucocorticoids have more or less consistently been shown to increase $o b$ gene expression 
and leptin secretion in vivo in both normal rats and humans (Larsson and Ahren, 1996; De Vos et al., 1995; Papaspyrou-Rao et al., 1997), as well as in vitro in primary cultures of adipocytes (Bradley and Cheatham, 1999; Murakami et al., 1995; Hardie et al., 1996; Halleux et al., 1998). With regard to the effect of insulin, the vast majority of studies indicate that insulin modulates leptin synthesis and secretion from adipocytes (Bradley and Cheatham, 1999; Saladin et al., 1995; Gettys et al., 1996; Hardie et al., 1996). However, a few studies have disagreed with these findings, leading to the suggestion that these disparate reports may have resulted from the use of different culture models. In support of an in vivo stimulatory effect, it was reported that $o b$ mRNA and leptin protein secretion in rats are tightly regulated by diet and insulin (Saladin et al., 1995). Under fasting conditions, $o b$ mRNA and leptin protein levels decreased to barely detectable levels but were restored to normal within 4 hours after re-feeding or administration of insulin. In addition, rats rendered hyperinsulinemic in clamp studies showed a marked increase in $o b$ mRNA, compared with controls.

\section{A. REGULATION OF LEPTIN MRNA AND LEPTIN SECRETION BY INSULIN AND DEXAMETHASONE}

To gain further insight into hormonal regulation of $o b$ gene expression and leptin secretion, we have studied the acute effects of insulin and dexamethasone (Dex), a synthetic glucocorticoid on leptin synthesis and secretion. In a recent study (Bradley and Cheatham, 1999), a 2-hour incubation of rat adipocytes with insulin had no effect on $a b$ mRNA levels (Figure 1A) but stimulated a two-fold increase in leptin secretion (Figure 1B). Dex, on the other hand, stimulated both a two- to four-fold increase in $o b$ mRNA (Figure 1A) and a two-fold increase in leptin secretion (Figure 1B), indicating that Dex acutely regulates $o b$ gene transcription in isolated rat adjpocytes. As shown in Figure 1A, concurrent treatment with both hormones did not stimulate $o b$ gene expression to any greater extent than did the individual agents. In contrast to its lack of effect on $o b$ mRNA, insulin stimulated a two-fold increase in leptin protein secretion. Similarly, incubation of adipocyte preparations with Dex showed a two-fold increase in leptin secretion. These data suggested that insulin regulates leptin synthesis/secretion via a potential post-transcriptional mechanism. Dex appears to do so via a transcriptionally mediated process.

To verify this hypothesis, we used the transcriptional inhibitor actinomycin D. Consonant with a post-transcriptional and transcriptional regulatory mechanism for insulin- and Dex-stimulated leptin secretion, respectively, actinomycin D blocked Dex-stimulated leptin secretion but did not affect insulin-stimulated leptin secretion (Bradley and Cheatham, 1999). Furthermore, as illustrated in Figure $2 \mathrm{~A}$, inhibition of protein synthesis with cycloheximide did not affect $o b$ mRNA accumulation but reduced total secreted leptin (Figure 2B). Interestingly, 

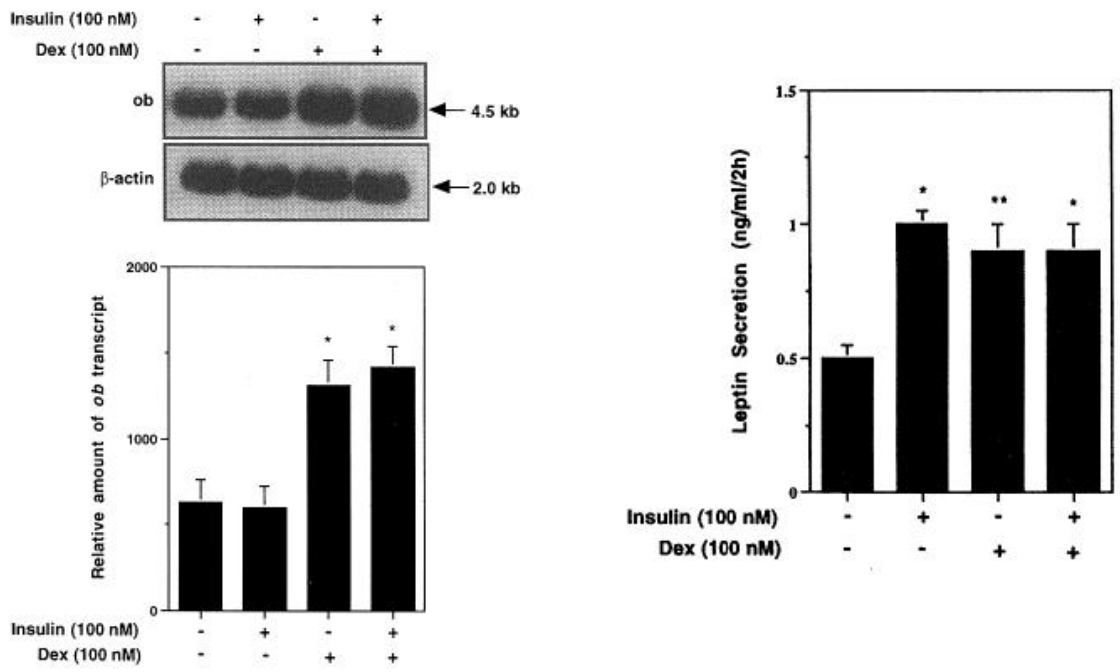

FIG. 1. (Left panels) Northern blot showing the individual and combined effects of insulin and dexamethasone on $o b$ gene expression in freshly isolated rat adipocytes. Adipocytes were incubated with and without either $100 \mathrm{nM}$ insulin, $100 \mathrm{nM}$ dexamethasone, or both simultaneously for 2 hours. Each lane was loaded with $10 \mu \mathrm{g}$ total RNA and hybridized with a mouse $o b$ cDNA probe. Densitometric scanning was used to determine the relative amount of $o b$ transcript. Blots were stripped and reprobed with a human $\beta$-actin cDNA probe as a control for RNA integrity and loading. (Right panels) Individual and combined effects of insulin and dexamethasone on leptin secretion from freshly isolated rat adipocytes. Incubation conditions were those described above. Leptin secreted into the conditioned medium was measured using a commercially available rat leptin radioimmunoassay (RIA) kit. All results are expressed as the mean \pm S.E.M. and are representative of three independent experiments $\left(\mathrm{n}=8\right.$ per assay). ${ }^{* \mathrm{P}}<0.05$ vs. control $(-/-) ;{ }^{* *} \mathrm{P}<0.02$ vs. control $(-/-)$. [Reprinted with permission from Bradley, R.L., and Cheatham, B. Diabetes 48, 272-278, 1999. Copyright by the American Diabetes Association.]

despite this decrease, insulin (but not Dex) was still able to stimulate a two-fold increase in leptin secretion by rat adipocytes relative to control cells in the presence of cycloheximide (Figure 2B). These data suggest that insulin, but not Dex, is able to stimulate secretion of a small, pre-existing, intracellular pool of leptin-containing vesicles. However, de novo protein synthesis is required for the full insulin-stimulated response.

\section{B. INSULIN-REGULATED SIGNALING PATHWAYS AND LEPTIN SECRETION}

Insulin regulates a variety of intracellular growth and metabolic processes (Cheatham and Kahn, 1995). Early events in insulin action involve the insulin- 
(A)

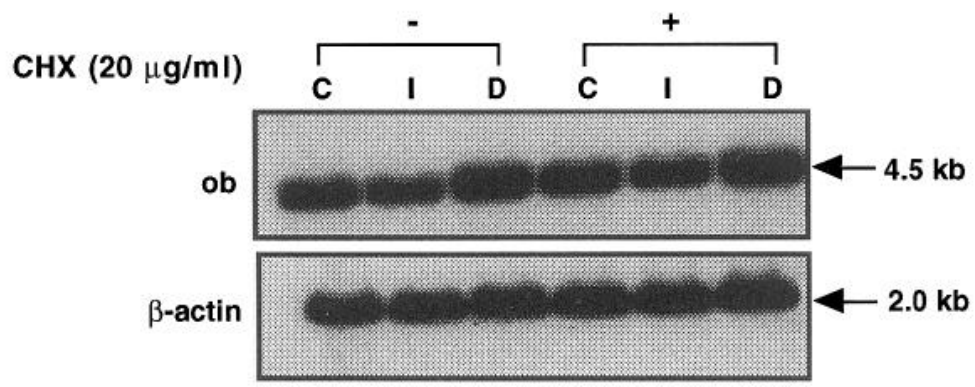

(B)

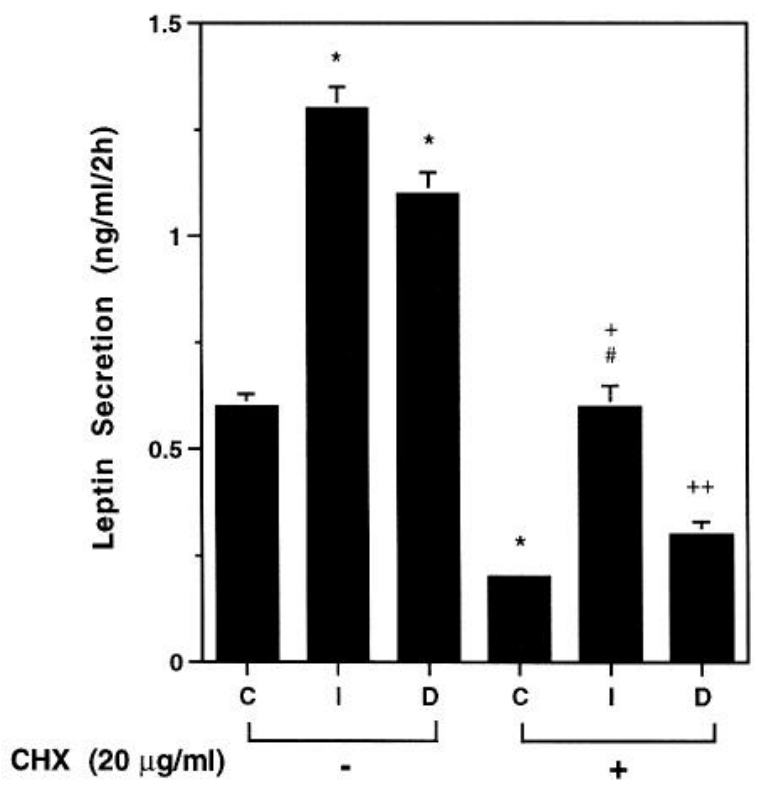

FIG. 2. (A) Northern blot showing the effect of the protein synthesis inhibitor cycloheximide (CHX) on $o b$ gene expression in control (C), insulin- (I), and dexamethasone- (D) treated rat adipocytes. Freshly isolated adipocytes were preincubated in the absence and presence of $20 \mu \mathrm{g} / \mathrm{ml} \mathrm{CHX}$ for 30 minutes. The conditioned medium was changed and adipocytes were incubated for 2 hours with and without $100 \mathrm{nM}$ insulin or $100 \mathrm{nM}$ dexamethasone in the absence and presence of CHX (20 $\mu \mathrm{g} / \mathrm{ml}$ ). Each lane was loaded with $10 \mu \mathrm{g}$ total RNA and membranes hybridized with a mouse $o b$ cDNA probe. Membranes were stripped and reprobed with a human $\beta$-actin cDNA probe as a control for RNA integrity and loading. (B) Effect of CHX $(20 \mu \mathrm{g} / \mathrm{ml})$ on leptin secretion. Secreted leptin contained in the conditioned medium from the 2-hour incubation described above was measured by RIA. Results are the mean \pm S.E.M. for 12 rats. ${ }^{*} \mathrm{P}<0.05$ vs. control minus $\mathrm{CHX} ;+\mathrm{P}<0.05$ vs. insulin treated minus $\mathrm{CHX}$; $\mathrm{P}<0.02$ vs. control plus $\mathrm{CHX} ;++\mathrm{P}<0.05$ vs. dexamethasone treated minus CHX. [Reprinted with permission from Bradley, R.L., and Cheatham, B. Diabetes 48, 272-278, 1999. Copyright by the American Diabetes Association.] 
stimulated activation of the insulin receptor and phosphorylation of intracellular substrates, including insulin receptor substrates 1 and 2 (IRS- 1 and IRS-2) and Shc. These tyrosine-phosphorylated proteins then act as docking sites for proteins containing SH2 domains such as Grb2, phosphatidylinositol (PI) 3-kinase, and the tyrosine phosphatase, SHP2. These protein-protein interactions, in turn, lead to regulation of more-distal events, including activation of Ser/Thr phosphorylation cascades that result in activation of mitogen-activated protein kinase (MAPK), pp90 S6 kinase, and pp70 S6 kinase. The end result of this series of events is the modulation of many of insulin's final biological responses (Cheatham and Kahn, 1995). Using specific inhibitors of PI 3-kinase, MAPK kinase (MEK), and pp70 S6 kinase, we have evaluated signaling pathways involved in the acute phase of insulin- and Dex-stimulated leptin synthesis/secretion. The effects of the PI 3-kinase inhibitor LY294002; the MEK inhibitor PD98059; and the immunosuppressant rapamycin on both insulin- and Dex-stimulated leptin mRNA secretion were determined. During a 2-hour incubation, basal levels of secreted leptin were not affected by any of the inhibitors (Figure 3 ). However, all three inhibitors markedly decreased both insulin- and Dex-stimulated leptin secretion (Figure 3). These findings suggest that a complex set of signaling pathways mediate insulin- and Dex-stimulated leptin production. These pathways involve multiple steps that are PI 3-kinase dependent as well as steps that are sensitive to the MEK inhibitor PD98059 and the immunosuppressant rapamycin.

\section{MELANIN-CONCENTRATING HORMONE REGULATES LEPTIN SECRETION}

More recently, the orexigenic (appetite-stimulating) neuropeptide, melaninconcentrating hormone $(\mathrm{MCH})$, has emerged as a regulator of leptin production by rat adipocytes (Bradley et al., 2000). MCH is a hypothalamic peptide important in the regulation of feeding behavior, primarily via uncharacterized pathways in the central nervous system (CNS). Leptin is known to mediate some of its actions through several hypothalamic neuropeptides (Elmquist et al., 1998). Indeed, $\mathrm{MCH}$-expressing neurons may be an important target of leptin action in the CNS, as $\mathrm{MCH}$ levels rise dramatically in the absence of leptin and also respond to fasting ( $\mathrm{Qu}$ et al., 1996). In addition, adipocytes express a number of receptors for both hormones and neuropeptides, including peptides involved in the regulation of appetite, and it is possible that other peptides may regulate leptin responses. Very-recent studies show MCH to modulate leptin production (Bradley et al., 2000 ). In these studies, $\mathrm{MCH}$ stimulated a two-fold increase in leptin secretion by isolated rat adipocytes after 4 hours of treatment. This increase in secreted leptin was preceded by a rapid and transient increase in $o b$ mRNA levels. As shown in Figure 4, MCH stimulated a 2.5 -fold increase in $o b$ mRNA within 1 hour of treatment, followed by a decline to basal levels within 4 hours. Thus, 


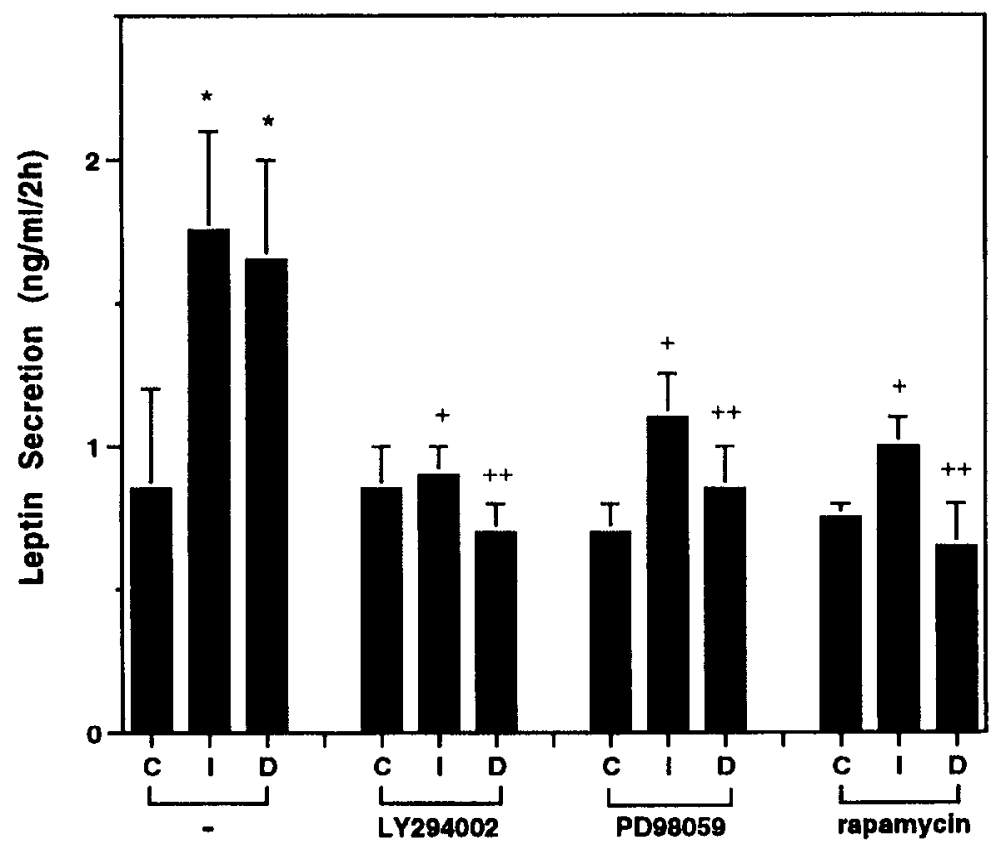

FIG. 3. Effects of the PI 3-kinase inhibitor LY294002, the MEK inhibitor PD98059, and the immunosuppressant rapamycin on leptin secretion from control (C), insulin- (I), and dexamethasone(D) treated rat adipocytes. Adipocytes were incubated in the absence and presence of $50 \mu \mathrm{M}$ LY294002, $10 \mu \mathrm{M}$ PD98059, or $20 \mathrm{nM}$ rapamycin for 30 minutes. The conditioned medium was changed and adipocytes incubated for 2 hours with and without $100 \mathrm{nM}$ insul in or $100 \mathrm{nM}$ dexamethasone in the absence and presence of each inhibitor at the aforementioned concentrations. Secreted leptin contained in the conditioned medium was measured by RIA. Results are the mean \pm S.E.M. for three independent experiments $\left(n=14\right.$ per assay). ${ }^{*} P<0.05$ vs. control $(-) ;+P<0.05$ vs. insul in treated (-); ++ P<0.05 vs. dexamethasone treated (-). [Reprinted with permission from Bradley, R.L., and Cheatham, B. Diabetes 48, 272-278, 1999. Copyright by the American Diabetes Association.]

$\mathrm{MCH}$ acutely stimulates an increase in $o b$ gene expression in rat adipocytes, resulting in an increase in leptin protein production and secretion (Bradley et al., 2000). In addition, we found that the $\mathrm{MCH}$ receptor, a seven-transmembrane domain G-protein-coupled receptor termed SLC-1 (Chambers et al., 1999; Saito et al., 1999), expressed in adipocytes (Figure 5). These data suggest that fat cells are targets of $\mathrm{MCH}$ or an $\mathrm{MCH}$-like peptide under physiological conditions. These observations also represent the first cultured-cell model for signaling via endogenous $\mathrm{MCH}$ receptors. We did not find $\mathrm{MCH}$ expressed in WAT (Bradley et al., 2000). At present, the exact physiological role of $\mathrm{MCH}$-stimulated leptin secretion is unclear. The cellular origin of $\mathrm{MCH}$ in peripheral tissues is unknown but circulating levels of $\mathrm{MCH}$ or an $\mathrm{MCH}-$ like peptide can be detected in rat plasma 

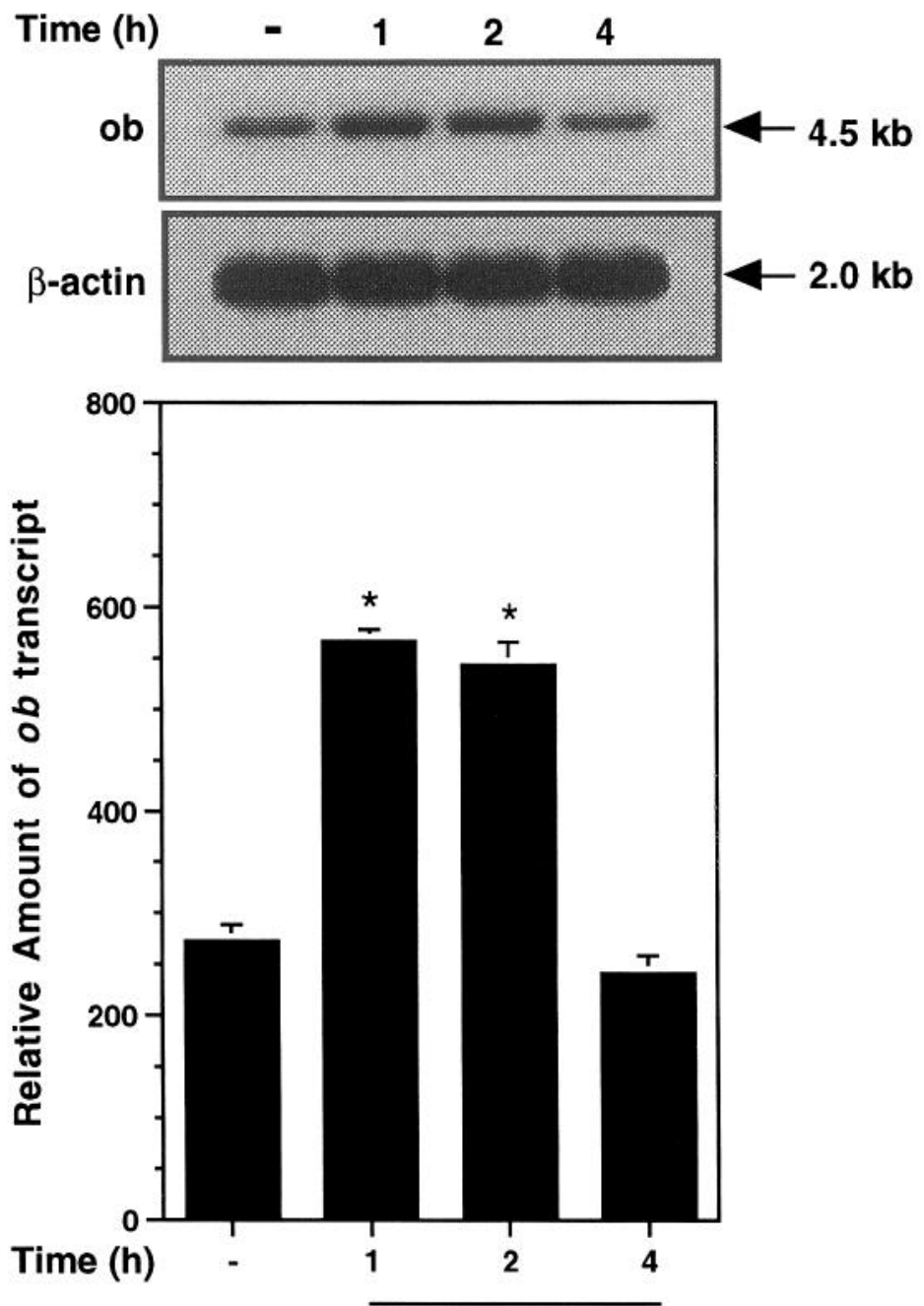

$\mathrm{MCH}$

FIG. 4. Northern blot showing the effect of $\mathrm{MCH}$ on $o b$ gene expression in isolated rat adipocytes derived from epididymal fat pads. Cells were incubated in the absence (-) and presence of $1 \mu \mathrm{M} \mathrm{MCH}$ as indicated for up to 4 hours. Total RNA was isolated from cells collected at each time-point. Each lane was loaded with $10 \mu \mathrm{g}$ total RNA and hybridized with a mouse $o b$ cDNA probe. Densitometric scanning was used to determine the relative amount of $o b$ transcript. Blots were stripped and reprobed with a human $\beta$-actin cDNA as a control for RNA integrity and loading. Results are means \pm S.E.M. for two independent experiments ( $\mathrm{n}=8$ per assay). ${ }^{*} \mathrm{P}<0.05 \mathrm{vs}$. control $(-)$. [Reprinted with permission from Bradley, R.L., Kokkotou, E.G., Maratos-Flier, E., and Cheatham, B. Diabetes 49, 1073-1077, 2000. Copyright by the American Diabetes Association.] 


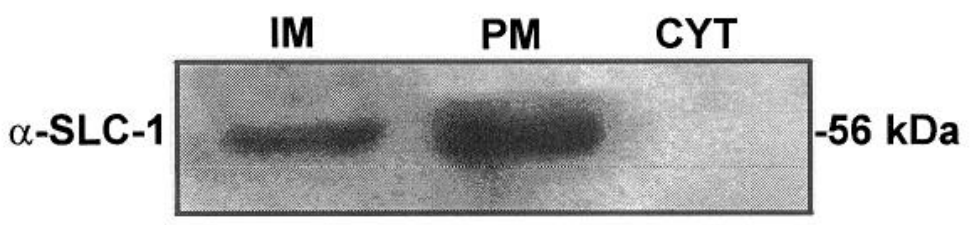

FIG. 5. Immunoblot showing the presence of SLC-1 protein in rat adipocytes. Membrane fractions were prepared from rat adipocytes derived from epididymal fat pads. Aliquots $(50 \mu \mathrm{g})$ of purified plasma membrane (PM), total internal membrane (IM), or cytosol (CYT) were solubilized in SDS-PAGE sample buffer, resolved by SDS-PAGE, transferred to nitrocellulose, and subjected to immunoblotting with a polyclonal $\alpha$-SLC-1 peptide antibody. Immunoreactive material was detected using $\left[{ }^{125} \mathrm{I}\right]$-labeled protein $\mathrm{A}$, followed by autoradiography. Results are representative of three independent experiments. [Reprinted with permission from Bradley, R.L., Kokkotou, E.G., MaratosFlier, E., and Cheatham, B. Diabetes 49, 1073-1077, 2000. Copyright by the American Diabetes Association.]

(Bradley et al., 2000). Finally, these data suggest a potential feedback mechanism between the brain and adipose tissue and further underscore the complexity of the cross-talk between the neuroendocrine systems mediating energy homeostasis as well as the ability of the adipocyte to respond to a wide range of afferent signals.

\section{Vesicle Transport Pathways in Adipocytes}

It is clear that adipocytes secrete a wide variety of proteins that affect numerous cell biological and metabolic pathways. However, very little is known regarding the components of the intracellular secretory pathways through which these proteins transit and ultimately exit the adipocyte. The following section summarizes some of the known components of the regulated pathway, discusses a newly identified protein (pantophysin) that may play a multifunctional role in vesicle biogenesis and transport, and describes the characteristics of intracellular trafficking of leptin-containing vesicles.

\section{A. COMPONENTS OF THE REGULATED SECRETORY PATHWAY IN ADIPOCYTES}

Insulin's primary physiological role is maintenance of glucose homeostasis via inhibition of hepatic glucose production and stimulation of glucose uptake into insulin-sensitive tissues: adipose, skeletal, and cardiac muscle (Birnbaum, 1992). Insulin stimulates the rate of glucose uptake into these tissues 10- to 20 -fold. This is accomplished by an insulin-stimulated translocation of the Glut4 glucose transporter protein from a unique, intracellular vesicular compartment to the plasma 
membrane (Birnbaum, 1992). The mechanism underlying translocation of Glut4 is the best-characterized, acutely regulated vesicle transport process in adipocytes. Approaches to define this mechanism have focused on determining the insulinregulated signaling pathways involved and identifying the molecular components utilized in directing movement and fusion of the Glut4-vesicle to the plasma membrane. A detailed review of this process by Pessin and colleagues can be found in this volume (Chapter 9); therefore, we will only touch on some highlights, emphasizing the components in this vesicle transport pathway.

Multiple lines of evidence have established a requirement for insulin-stimulated activation of PI 3-kinase as an upstream regulator or Glut4 translocation. More recently, protein kinase $\mathrm{B}(\mathrm{PKB})$ and the atypical $\mathrm{PKCs}(\mathrm{PKC} \lambda$ and $\mathrm{PKC} \zeta$ ) have been implicated as potential downstream targets of PI 3-kinase. However, their exact roles in signaling to the Glut 4 vesicles are unknown. Clearly, much remains to be learned regarding the exact signaling cascade. However, in an effort to link signaling pathways to the Glut4 vesicle, several laboratories have focused on identifying proteins in adipocytes that are involved in regulated exocytosis. These studies found that adipocytes express proteins previously shown to mediate acute regulated vesicle transport events in neuroendocrine tissues. The research suggested that translocation of Glut4 may utilize machinery similar to that found in these systems (St-Denis and Cushman, 1998). These proteins include soluble N-ethylmaleimide-sensitive fusion (NSF) protein attachment protein receptors, or SNARE proteins. Through defined protein-protein interactions, members of the SNARE family of membrane-associated proteins can selectively mediate homotypic and heterotypic membrane fusion (Pfeffer, 1999; Hay and Scheller, 1997). The current model for SNARE-mediated docking and fusion states that a vesicleassociated SNARE ( $v$-SNARE) interacts with cognate target-membrane SNAREs (t-SNARE) to mediate the interaction between two separate membrane populations. This minimal complement of a v-SNARE and t-SNAREs is sufficient to mediate fusion in vitro (Weber et al., 1998).

VAMP-2 is a v-SNARE in adipocytes associated with the Glut4 vesicle (St-Denis and Cushman, 1998). Syntaxin-4 and SNAP-23 are the cognate tSNARE molecules expressed in adipocytes and found almost exclusively on the plasma membrane (St-Denis and Cushman, 1998). Studies from this lab and others have provided multiple lines of evidence for a specific role of these proteins in Glut4 translocation (Cheatham et al., 1996; St-Denis and Cushman, 1998; Pessin et al., 1999). The current minimal model for SNARE-mediated Glut4 vesicle trafficking suggests that VAMP-2 on the Glut4 vesicle forms a stable, heterotrimeric complex with syntaxin-4 and SNAP-23 present at plasma membrane and brings the Glut4 vesicle in contact with the plasma membrane driving fusion. Disruption of the heterotrimeric complex and regeneration of the individual SNARE proteins are thought to involve the ATPase activity associated with NSF 
and the soluble NSF attachment protein, $\alpha$-SNAP. This "priming step" prepares the SNARE proteins for further fusion events (Pfeffer, 1999; Rice and Brunger, 1999; Hay and Scheller, 1997).

The regulation of SNARE-complex formation is currently an area of intense focus. Munc $18 \mathrm{c}$ and Synip have been identified as potential regulators of SNAREcomplex formation in adipocytes. Munc $18 \mathrm{c}$ is a member of a family of syntaxin-4binding proteins and, when bound to syntaxin-4, inhibits the binding of VAMP-2. Thus, Munc18c is thought to be a negative regulator of SNARE-complex formation (Tellam et al., 1997; Tamori et al., 1998). Synip was isolated as a syntaxin4-binding protein in a yeast two-hybrid screen (Min et al., 1999). It contains several potential functional domains, including a PDZ domain, a coiled-coil region, and a WW domain. Synip also is enriched in adipose and skeletal muscle. Synip is associated with syntaxin- 4 in the basal state. The current model for Synip function involves the interaction of its $\mathrm{COOH}$-terminal domain with syntaxin-4, while the $\mathrm{NH}_{2}$-terminal domain responds to an as-yet-undefined insulin-generated signal. It should be noted that, other than Glut4 vesicles, a functional role for SNARE proteins in mediating exocytosis of other adipocyte-derived products has not been reported.

\section{B. PANTOPHYSIN IS A PHOSPHOPROTEIN COMPONENT OF ADIPOCYTE TRANSPORT VESICLES}

We have recently identified and have partially characterized pantophysin as another potential regulator of SNARE-complex formation and as a component of numerous intracellular vesicles (Brooks et al., 2000). Pantophysin is a homologue of the neuroendocrine-specific protein synaptophysin, sharing a 43 percent overall amino acid sequence identity (Haass et al., 1996). It contains four predicted transmembrane domains that are highly homologous to synaptophysin. In contrast, the $\mathrm{NH}_{2}$ - and $\mathrm{COOH}$-termini are quite divergent. Synaptophysin contains an extended $\mathrm{COOH}-$ terminus that includes a tyrosine-rich domain not present in pantophysin. Synaptophysin is fairly well characterized and, although its exact function is unclear, has been implicated in regulating SNARE-SNARE interactions, formation of fusion pores, vesicle biogenesis, and formation of lipid microdomains at the cell surface (Elferink and Scheller, 1995; Thiele et al., 2000). Thus, based upon these data and the homology between the proteins, pantophysin is an intriguing molecule that may play a multifunctional role in vesicle biogenesis and transport. Therefore, we have included a description of some of the characteristics of pantophysin.

\section{Expression of Pantophysin and Its Subcellular Distribution}

Pantophysin mRNA is widely expressed in mouse tissues and is relatively abundant in adipose tissue. Pantophysin mRNA increases (approximately two- 
fold) during adipogenesis of 3T3-L1 cells (Brooks et al., 2000). Immunoblot analysis indicates pantophysin is present exclusively in membrane fractions and relatively evenly distributed in the plasma membrane and two internal membrane fractions, the low (LDM)- and high (HDM)-density microsomes. Like synaptophysin, pantophysin is glycosylated and migrates as a broad band on SDS-PAGE. Following deglycosylation with $\mathrm{N}$-glycosidase $\mathrm{F}$, pantophysin migrates at its predicted molecular mass of $28.5 \mathrm{kDa}$ (Brooks et al., 2000). Interestingly, its pattern of glycosylation changes during differentiation of 3T3-L/ cells to adipocytes. In addition, we observed that the glycosylation pattern of pantophysin varies considerably in a tissue-dependent manner. The role of this variable glycosylation is unclear but may be involved in membrane targeting or perhaps in functional differences between tissues.

\section{Pantophysin Is a Component of Glut4 Vesicles}

Compared to insulin-stimulated Glut4 translocation, insulin stimulates only a modest, but significant, redistribution of pantophysin from an intracellular vesicular compartments to the plasma membrane. Thus, some pantophysin trafficks in an insulin-dependent manner similar to that of Glut4, although to a lesser extent. Further analysis of pantophysin vesicles by sucrose gradient ultracentrifugation demonstrated that pantophysin and Glut4 exhibited overlapping distribution profiles. Analysis of immunopurified vesicles revealed that Glut4 vesicles contain pantophysin. Both Glut4 and pantophysin were depleted from this vesicle population following treatment with insulin (Figure 6). However, only a subpopulation of the total immunopurified pantophysin vesicles contained insulin-responsive Glut4, consistent with the modest, insulin-stimulated redistribution of pantophysin (Brooks et al., 2000). Taken together, these data suggest pantophysin is present on a variety of intracellular vesicles.

\section{Pantophysin Interacts with VAMP-2}

Synaptophysin has been shown to interact with the v-SNAREs in neuroendocrine tissues (Calakos and Scheller, 1994). Consistent with this observation, we found pantophysin associated with VAMP-2 but not VAMP-3 in adipocytes (Figure 7). The interaction of VAMP with synaptophysin has been shown to block the interaction of VAMP with syntaxin (Calakos and Scheller, 1994). Thus, it has been suggested that the synaptophysin/VAMP interaction may be a regulatory mechanism in SNARE-SNARE interaction or perhaps is involved in recycling of VAMP into a newly formed regulated vesicle. Our data suggest that pantophysin may play a similar role; however, much more work is necessary. Currently, we are mapping domains on VAMP-2 that are involved in the interaction with pantophysin. 


\title{
IPVs
}
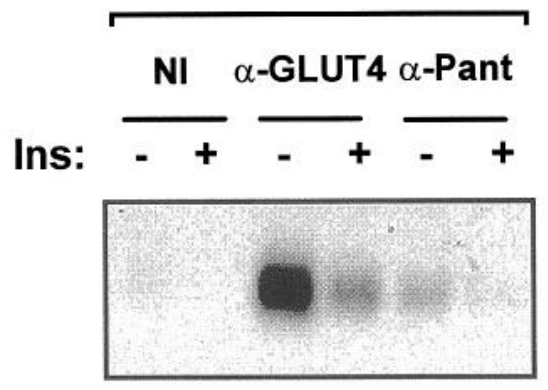

\section{$\alpha$-GLUT4}

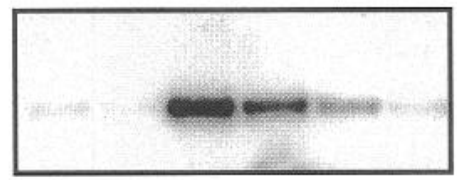

\author{
$\alpha-$ IRAP
}

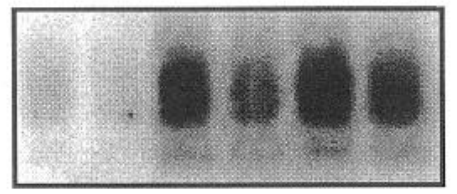

$\alpha$-Pant

FIG. 6. Immunopurified GLUT4- and pantophysin-containing vesicles analyzed by immunoblot with $\alpha$-GLUT4, $\alpha$-pantophysin, and $\alpha$-IRAP. Fully differentiated 3T3-L1 adipocytes were incubated in DMEM/ $0.1 \%$ bovine serum albumin (BSA) overnight and treated for 10 minutes in the absence (-) or presence $(+)$ of $100 \mathrm{nM}$ insulin. Immunopurified vesicles (IPVs) were prepared from LDM fractions using nonimmune (NI) serum, $\alpha$-GLUT4-, or $\alpha$-pantophysin (pant). Immunopurified vesicles were solubilized in SDS-PAGE sample buffer, separated on $10 \%$ SDS-PAGE, and electrophoretically transferred to nitrocellulose for immunoblotting with $\alpha$-GLUT4 (top), $\alpha$-IRAP (middle), or $\alpha$-pantophysin (bottom). Immunoreactive material was detected by $\left[{ }^{125} \mathrm{I}\right]-$ labeled protein $\mathrm{A}$ and subsequent autoradiography. Results are representative of three or more independent experiments. [Reprinted with permission from Brooks, C.C., Scherer, P.E., Cleveland, K., Whittemore, J.L., Lodish, H.F., and Cheatham, B. J. Biol. Chem. 275, 2029-2036, 2000. Copyright The American Society for Biochemistry \& Molecular Biology.]

\section{Pantophysin Is Phosphorylated}

Finally, another interesting characteristic of pantophysin is its phosphorylation. In [ $\left.{ }^{32} \mathrm{P}\right]$-orthophosphate-labeled 3T3-L1 adipocytes, pantophysin is phosphorylated in the basal state. Insulin or serum does not affect this phosphorylation. However, we did observe an insulin-stimulated phosphorylation of a $77-\mathrm{kDa}$ protein associated with $\alpha$-pantophysin immunoprecipitates (Brooks et al., 2000). 


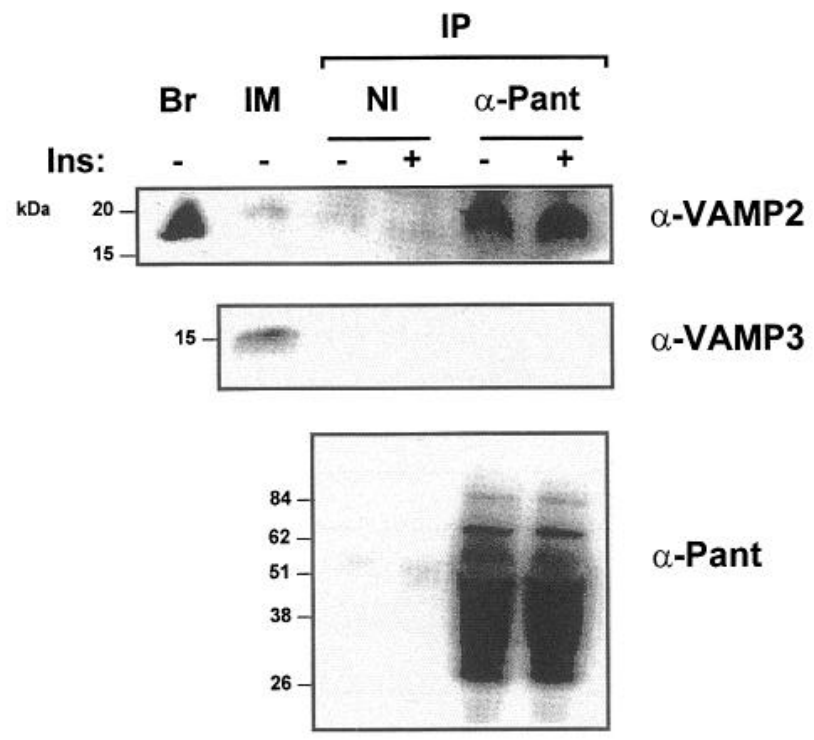

FIG. 7. Interaction of pantophysin and VAMP2 in $\alpha$-pantophysin immunoprecipitates. Fully differentiated 3T3-L1 adipocytes were incubated in DMEM/0.1\% BSA overnight. Cells were incubated for 10 minutes in the absence (-) or presence (+) of $100 \mathrm{nM}$ insulin, lysed, and immunoprecipitates using nonimmune (NI) or $\alpha$-pantophysin (pant) serum prepared. Samples were solubilized in SDS-PAGE sample buffer, separated on SDS-PAGE, and electrophoretically transferred to nitrocellulose membranes for immunoblotting with $\alpha$-VAMP2, $\alpha$-VAMP3, or $\alpha$-pantophysin. Immunoreactive material was detected by $\left[{ }^{125} \mathrm{I}\right]$-labeled protein $\mathrm{A}$ and subsequent autoradiography. IP $=$ immunoprecipitate; $\mathrm{Br}=40 \mu \mathrm{g}$ brain lysate; $\mathrm{IM}=20 \mu \mathrm{g}$ 3T3-L1 adipocyte internal membranes (LDM + HDM). The data presented are representative of three or more independent experiments. [Reprinted with permission from Brooks, C.C., Scherer, P.E., Cleveland, K., Whittemore, J.L., Lodish, H.F., and Cheatham, B. J. Biol. Chem. 275, 2029-2036, 2000. Copyright The American Society for Biochemistry \& Molecular Biology.]

The role of phosphorylation of pantophysin is unclear. Identification of sites of phosphorylation and a potential regulation of this phosphorylation are underway.

Although the functional role of pantophysin in vesicle trafficking is unclear, its presence on Glut4 vesicles is consistent with the emerging role of SNAREcomplex and related proteins in regulated vesicle transport in adipocytes. Recently, we observed that microinjection of antibodies against pantophysin or microinjection of a $\mathrm{COOH}$-terminal fragment of pantophysin inhibited insulinstimulated Glut4 translocation (L. Foster, B. Cheatham, and A. Klip, unpublished data). The exact mechanism of this inhibition is unclear but is consistent with a role of this protein in vesicle transport/biogenesis. In addition, since pantophysin is present on a variety of intracellular vesicles, we have begun using it as a marker to help define the trafficking and contents of uncharacterized vesicles in adipo- 
cytes. As will be discussed, we show that leptin is a cargo protein in a subpopulation of pantophysin-containing vesicles that is distinct from Glut4-containing vesicles. In addition, the predicted roles of synaptophysin in a variety of vesicle transport functions, vesicle biogenesis, and formation of lipid microdomains at the cell surface suggest that pantophysin may play an important role in one or more of these processes.

\section{A CONSTITUTIVE SECRETORY PATHWAY IN ADIPOCYTES: INTRACELLULAR TRAFFICKING OF LEPTIN-CONTAINING VESICLES}

As discussed earlier, insulin stimulates leptin secretion by primary rat adipocytes. However, the extent to which this effect is mediated by a regulated secretory pathway vs. a constitutive pathway remains unclear. In one study, insulin appeared to acutely stimulate exocytosis of leptin directly from an endoplasmic reticulum (ER)-enriched compartment, bypassing accumulation in identifiable, regulated secretory vesicles (Barr et al., 1997). Our initial studies suggested that the major component of insulin-stimulated leptin secretion trafficks along a constitutive path requiring de novo protein synthesis. However, we also showed that, in the presence of cycloheximide, insulin can stimulate exocytosis of a small, preformed pool of leptin-containing vesicles (Bradley and Cheatham, 1999). These data suggest that leptin secretion is primarily via a constitutive pathway; however, there is a small population of leptin-containing vesicles able to undergo acutely regulated exocytosis. These observations are similar to the characteristics for the stimulated secretion of Acrp30 (Bogan and Lodish, 1999). To better define these pathways, we have analyzed and characterized leptin-containing vesicles in rat adipocytes.

\section{Subcellular Distribution of Leptin in Rat Adipocytes}

To analyze intracellular pools of leptin, rat adipocytes were homogenized and the nuclear/mitochondrial supernatant subjected to subcellular fractionation by differential centrifugation to yield two internal membrane fractions, the LDM and HDM, respectively. The LDM is enriched with Golgi-derived membranes as well as the insulin-sensitive pool of Glut4 vesicles, whereas the HDM is enriched with ER-derived markers. As shown in Figure 8A - and consistent with the expected enrichment of specific organellar membranes in the HDM and LDM - both ER-specific proteins translocon-associated protein- $\alpha$ (TRAP- $\alpha$ ) and calnexin were highly enriched in the HDM and were undetectable in the LDM. The LDM was enriched with the Golgi markers mannosidase II and coat protein, $\beta$-COP. Furthermore, as shown in Figure 8B, intracellular leptin associates primarily with the HDM and insulin stimulates an increase in intracellular leptin exclusively in this compartment. This increased intracellular leptin was accompanied by a corresponding increase in secreted leptin. Under these conditions, there were no detectable changes in leptin protein levels in the LDM. These results also indicate 

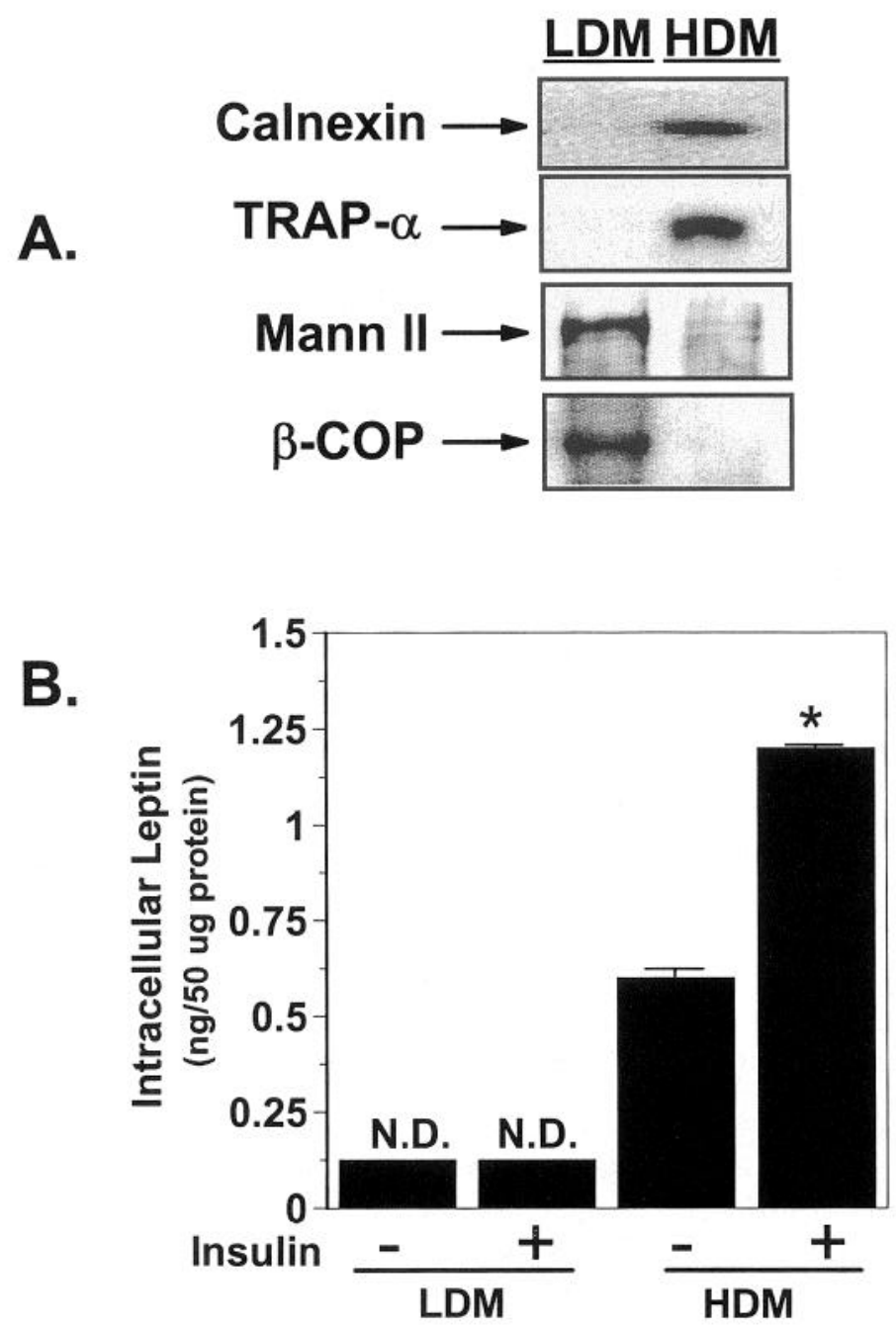

FIG. 8. Effect of insulin on the subcellular distribution of leptin. (A) Membrane fractions were prepared from freshly isolated rat adipocytes. An aliquot containing an equal amount of protein (10-25 $\mu \mathrm{g}$ ) from LDM or HDM was solubilized in SDS-PAGE sample buffer, resolved by SDS-PAGE, and electrophoretically transferred to nitrocellulose membranes. For marker enzyme assays, membranes were subjected to immunoblotting using primary antibodies for calnexin, TRAP- $\alpha$, mannosidase II (Mann II), or $\beta$-COP. (B) Leptin content was determined in HDM and LDM fractions from rat adipocytes incubated in the absence or presence of $100 \mathrm{nM}$ insulin for 2 hours. The leptin content of each sample was measured using a commercially available rat leptin RIA kit. Results are representative of three independent experiments ( $n=8$ per assay) and are expressed as the mean \pm S.E.M. N.D. $=$ below the limit of detection. ${ }^{*} \mathrm{P}<0.05 \mathrm{vs}$. HDM in the absence of insulin. 
that leptin-containing vesicles are distinct from the insulin-sensitive, Glut4-containing vesicles that are present in the LDM. Our findings are consistent with immunofluorescence data of Barr and coworkers (1997) that showed co-localization of leptin with the ER-specific protein calnexin and insulin stimulation of the release of leptin from this compartment.

\section{Effect of Brefeldin A on Leptin Secretion and Accumulation of Leptin in Golgi Compartments at $20^{\circ} \mathrm{C}$}

It is generally accepted that proteins destined for secretion leave the ER and transit through the Golgi for final processing on their way to the cell surface. Barr and colleagues (1997) showed that insulin stimulated the transport of leptin from the ER without any observable accumulation in secretory vesicles. They hypothesized that since leptin is not glycosylated, it is not retained and rapidly transits the Golgi. Similarly, we were unable to detect changes in leptin content in the Golgi-enriched LDM. To test this hypothesis, and to further define the intracellular localization of leptin and its transit through the secretory pathway, adipocytes were incubated in the absence or presence of brefeldin A, which causes Golgi disassembly. Brefeldin A treatment blocked both basal and insulin-stimulated leptin secretion from rat adipocytes (Figure 9A). As indicated in Figure 9B, this resulted in a dramatic accumulation of intracellular leptin (i.e., a 12-fold increase) in the HDM from basal cells. In the presence of brefeldin A, insulin stimulated an even-greater accumulation of intracellular leptin (i.e., a 24-fold increase). These findings suggest a role of intact Golgi membranes in secretion of leptin and further confirm that insulin stimulates an increase in intracellular leptin content. In addition, these data suggest that secretion of the proposed preformed, insulinsensitive pool of leptin-containing vesicles requires the presence of intact Golgi membranes. Thus, these preformed, insulin-sensitive, leptin-containing vesicles are most likely pre-Golgi or are derived from an intermediate Golgi compartment. Furthermore, the primary insulin-stimulated component is to increase leptin protein levels. This model is similar to that shown for another adipocyte-derived protein, Acrp30, in which a portion of Acrp30 is apparently sorted into regulated secretory vesicles whose initial exocytosis is stimulated by insulin. The remainder are sorted into vesicles that undergo constitutive exocytosis (Bogan and Lodish, 1999). The exact nature of this model of secretion in adipocytes is unclear and requires further analysis.

The brefeldin A experiments described here provide evidence for a role of the Golgi complex in leptin secretion. In an effort to show transit of leptin through the Golgi, we determined the extent of leptin secretion and its subcellular distribution in experiments performed at $20^{\circ} \mathrm{C}$. At this temperature, secretory proteins exit the ER and enter the Golgi, where they accumulate in late Golgi compartments (Matlin and Simons, 1983). At $20^{\circ} \mathrm{C}$, leptin secretion was completely 
A.

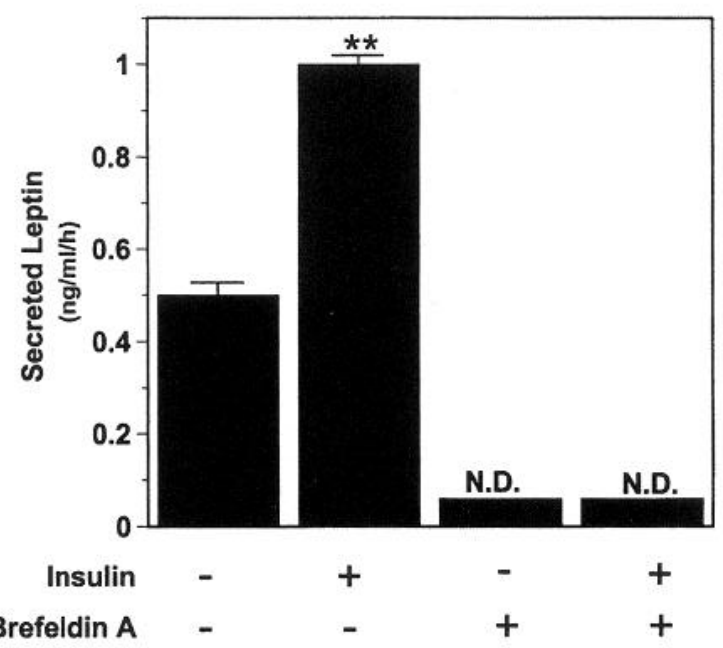

B.

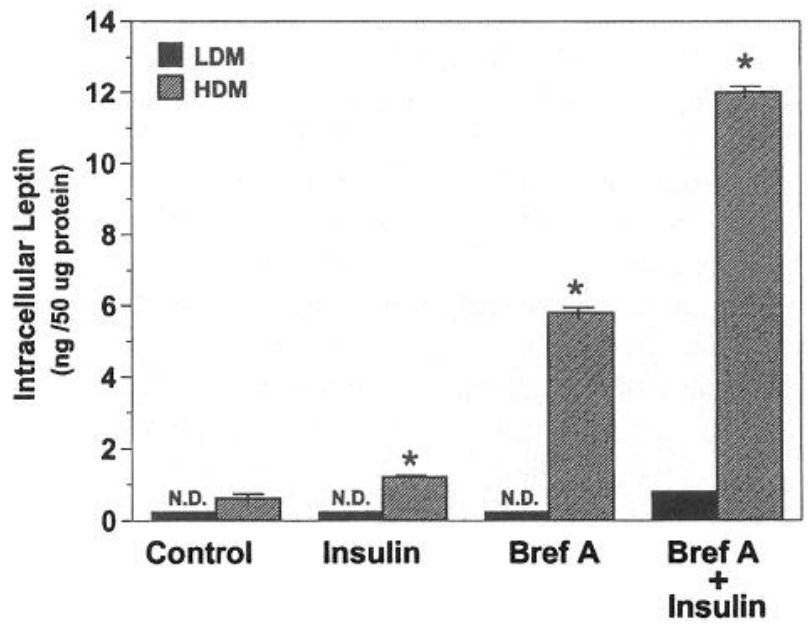

FIG. 9. Effect of brefeldin A on basal and insulin-stimulated leptin secretion and intracellular leptin content. Adipocytes were preincubated in the absence and presence of $20 \mu \mathrm{g} / \mathrm{ml}$ brefeldin A for 30 minutes. The conditioned medium was changed and the adipocytes were incubated for 2 hours with or without $100 \mathrm{nM}$ insulin in the absence or presence of $20 \mu \mathrm{g} / \mathrm{ml}$ brefeldin A. (A) Secreted leptin contained in the conditioned medium was measured by RIA. (B) HDM and LDM were prepared and the leptin content of each was measured by RIA. Results are means \pm S.E.M. for three independent experiments $(\mathrm{n}=10$ per assay). N.D. $=$ below the limit of detection. $* \mathrm{P}<0.05 \mathrm{vs}$. relative to control $\mathrm{HDM} ; * * \mathrm{P}<0.02$ vs. control. 
A.

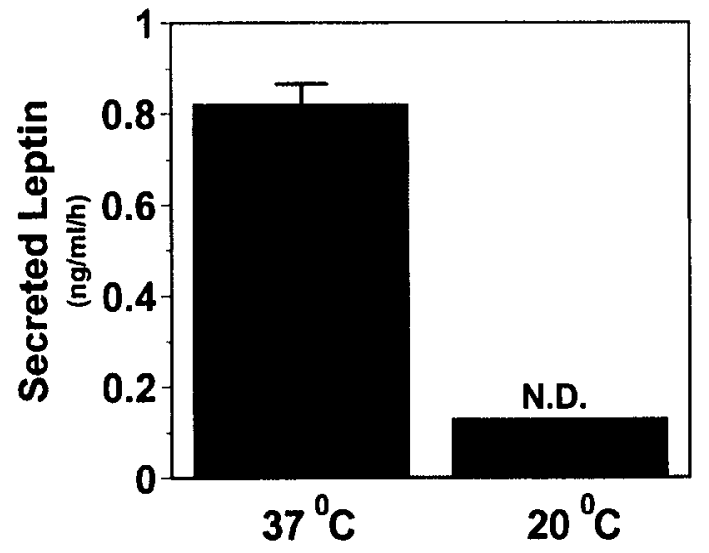

B.

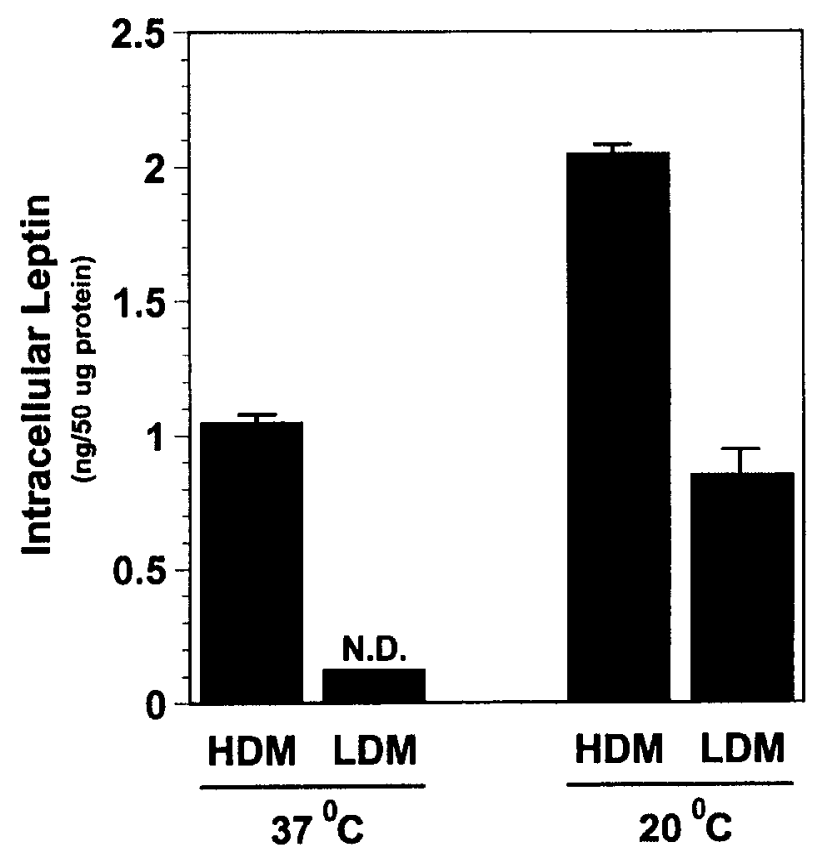

FIG. 10. Secretion and subcellular distribution of leptin at $20^{\circ} \mathrm{C}$. Isolated rat adipocytes were subjected to incubation at $37^{\circ} \mathrm{C}$ or $20^{\circ} \mathrm{C}$ for 1.5 hours. (A) Conditioned medium was subjected to RIA for leptin. (B) Cells were homogenized and HDM and LDM fractions prepared and analyzed for leptin content by RIA. Results are means \pm S.E.M. for two independent experiments. N.D.= below the limit of detection. 
inhibited (Figure 10A). Analysis of intracellular leptin showed a two-fold increase in HDM-derived leptin. Consistent with a block in exit from the Golgi at $20^{\circ} \mathrm{C}$, there was an approximately 10-fold increase in leptin content in the Golgi-enriched LDM compartment (Figure 10B).

\section{Analysis of Leptin-containing Vesicles by Sucrose Gradient Ultracentrifugation}

To further characterize LDM- and HDM-derived, leptin-containing intracellular vesicles, we performed velocity and density gradient ultracentrifugation. The distribution of total protein in LDM or HDM, as resolved by velocity gradient centrifugation, is shown in Figure 11A. Figure 11B shows a typical immunoblot for pantophysin contained in fractions derived from the gradients (fractions are shown from bottom to top, i.e., fraction 1 is bottom of the gradient). Figures $11 \mathrm{C}$ and 11D depict the velocity gradient profiles for leptin and pantophysin from the LDM and HDM, respectively. LDM-derived vesicles containing leptin fractionated near the bottom of the gradient and were largely separated from the total protein and pantophysin vesicles, suggesting there is little overlap of these markers in this subcellular compartment. In contrast, the profiles of pantophysin and

A.

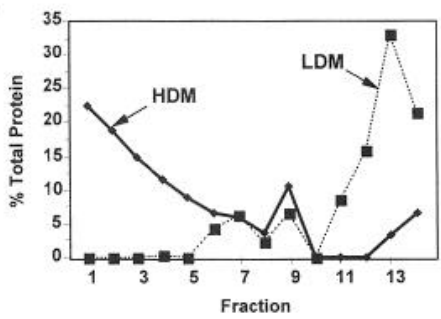

B.

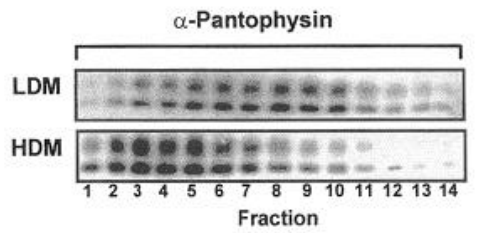

C.

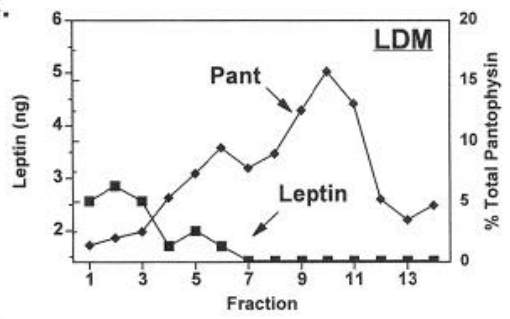

D.

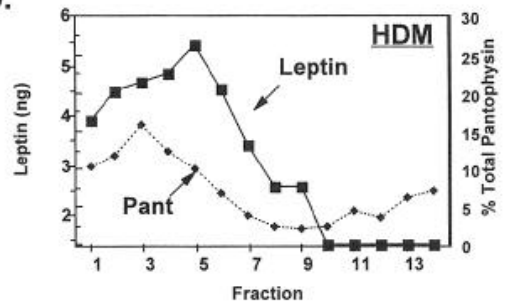

FIG. 11. Velocity gradient centrifugation analysis of subcellular fractions. LDM and HDM subcellular fractions were subjected to velocity gradient centrifugation. Fractions were collected from bottom (Fraction 1) to top (Fraction 14) and subjected to protein analysis (A). (B) Aliquots of each fraction were subjected to immunblot analysis with $\alpha$-pantophysin. (C) and (D) show a typical profile for pantophysin, as determined by densitometric scans of autoradiograms (dotted line) and leptin content as determined by RIA (solid line) from LDM and HDM, respectively. Results are representative of three or more independent experiments. 
leptin from HDM-derived vesicles indicate a significant overlap (Figure 11D) and suggest that these vesicles are of similar size.

\section{Immunopurified Pantophysin Vesicles Contain Leptin}

Gradient profiles of leptin and pantophysin from HDM-derived vesicles showed a significant overlap, which suggested that these vesicles were of similar size and buoyant density. The similar profiles of these proteins and the presence of pantophysin on various intracellular vesicles raised the possibility that leptin is potentially a cargo protein in a population of pantophysin-containing vesicles. To address this, pantophysin-containing vesicles were immunopurified. In these studies, internal membrane fractions were incubated with a nonrelated $\operatorname{IgG}$ or with an antibody specific for the C-terminus of pantophysin, then immunopurified vesicles (IPVs) were analyzed for leptin content and pantophysin. As illustrated in Figure 12A, immunoblotting showed that vesicles containing the two isoforms of pantophysin (native, $28.5 \mathrm{kDa}$, and glycosylated, $38 \mathrm{kDa}$ ) detected in rat adipocytes were specifically immunoadsorbed with $\alpha$-pantophysin but not with non-immune IgG. Subsequent analysis of the same IPVs by radioimmunoassay (Figure 12B) showed that leptin is, indeed, a resident cargo protein in a subpopulation of pantophysin-containing vesicles. Leptin was not detected in the nonimmune sample. Thus, using pantophysin as a marker and $\alpha$-pantophysin as an affinity reagent to purify these vesicles, we have been able to partially purify and enrich for leptin-containing vesicles. The exact origin of these vesicles and their content require further investigation.

\section{Summary and Conclusions}

The adipocyte is an important site of synthesis and secretion of factors that regulate a variety of metabolic processes. Alterations in the production of these factors are associated with - and can play a primary role in - the pathophysiology of several disease states, including obesity, hypertension, cardiovascular anomalies, hyperglycemia, insulin resistance, and type 1 and type 2 diabetes. Despitc the volume of protein cargo and vesicle traffic within the adipocyte, very little is known regarding the synthesis and secretion of adipocyte-secretory products. There have been significant advances in our understanding of the acute regulated translocation of Glut 4 . These include the signaling pathways downstream of IRS proteins and PI 3-kinase as well as SNARE proteins that comprise some of the molecular machinery necessary for docking and fusion of the Glut4 vesicles (see Figure 13 for a summary model). However, the pathways utilizcd by other secreted proteins have not been investigated to any significant extent. In an attempt to better define these pathways, we have analyzed the agonist-stimulated biosynthesis and secretion of leptin and characterized the intracellular vesicle 

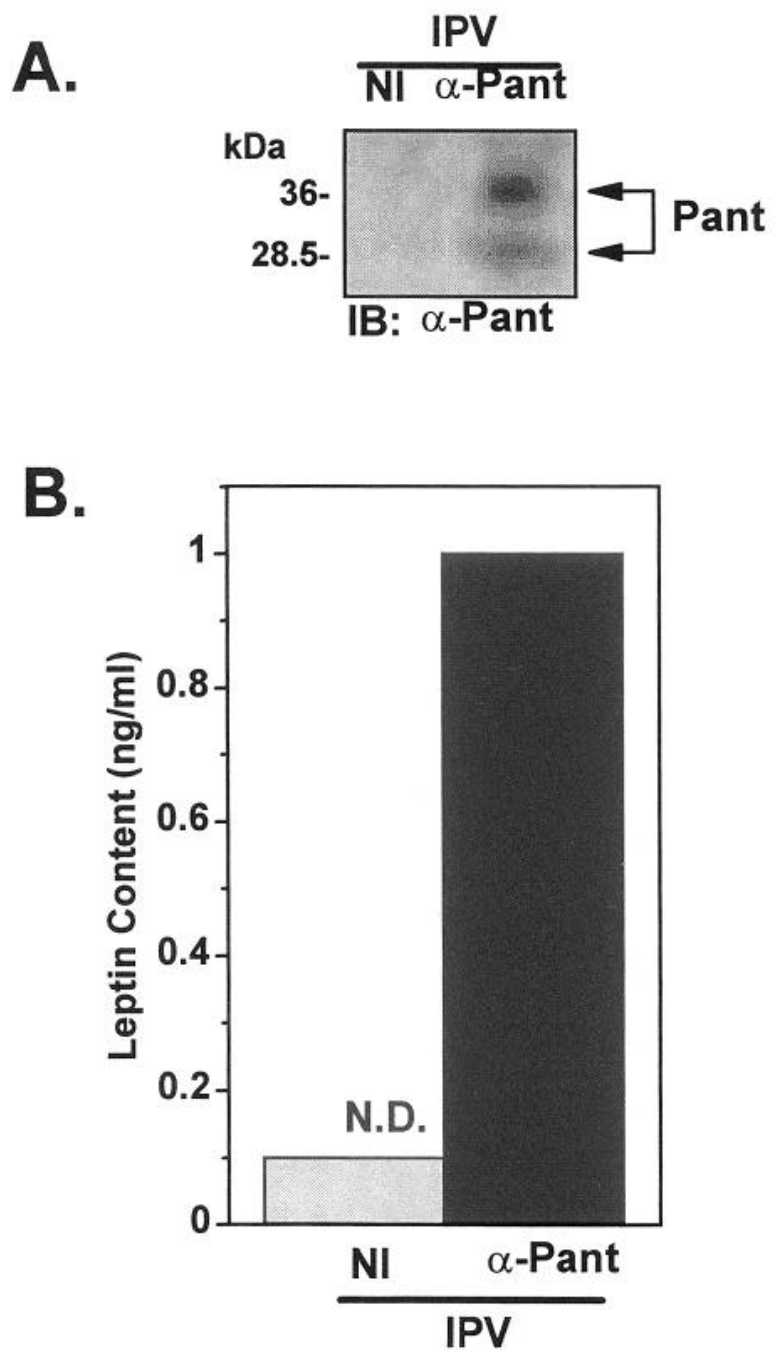

FIG. 12. Immunopurification of pantophysin-containing vesicles. Pantophysin-containing vesicles were purified from an intracellular membrane preparation by immunoadsorption using a non-immune IgG $(\mathrm{NI})$ or specific pantophysin antisera ( $\alpha$-Pant). Associated proteins were analyzed for pantophysin by immunoblot (A) or for leptin content (B) by RIA. Results are representative of two independent experiments. N.D. $=$ below the limit of detection. 


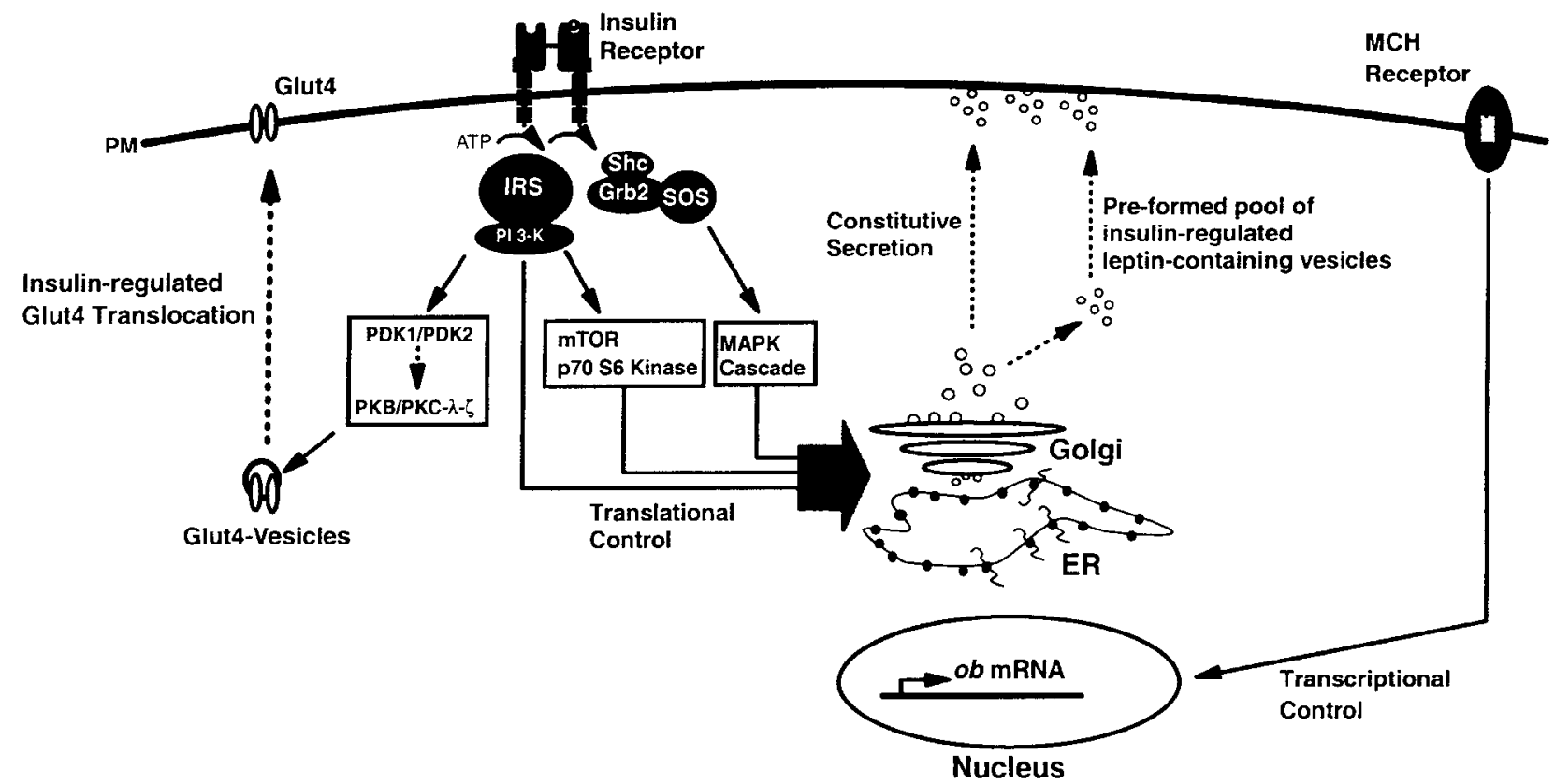

FIG. 13. A model of insulin-regulated vesicle transport pathways in adipocytes. Insulin stimulates the translocation of Glut4-containing vesicles from an intracellular compartment to the plasma membrane (PM). This involves signaling pathways requiring IRS proteins, PI 3-kinase, and the downstream kinases PDK1/PDK2, PKB, and the atypical PKCs $\lambda$ and $\zeta$. This process also requires SNARE proteins such as VAMP-2 on the Glut 4 vesicle and syntaxin-4 and SNAP-23 at the PM. Insulin-stimulated leptin secretion occurs via at least two components. The major component involves increases in the intracellular content of leptin, while a minor component is the insulin-stimulated release of a small, preformed pool of leptin-containing vesicles. These mechanisms require intact signaling downstream of PI 3-kinase, pp70 S6 kinase, and the MAPK cascade but are not dependent on ongoing transcription. In contrast, MCH-stimulated or glucocorticoid-stimulated leptin secretion occurs primarily via transcriptional mechanisms. 
transport of leptin-containing vesicles. Our findings suggest that insulin-stimulated leptin secretion involves at least two components. The major component is the ability of insulin to stimulate an increase in intracellular leptin content that appears to traffick out of the cell in a constitutive manner. A second, relatively minor component is the ability of insulin to stimulate the secretion of a small, preformed pool of leptin-containing vesicles. These pathways are independent of ongoing transcription but do require intact signaling pathways through PI 3-kinase, pp70 S6 kinase, and the MAPK cascade. We also report that leptin secretion is stimulated by treatment of adipocytes with glucocorticoids or $\mathrm{MCH}$. These pathways appear primarily to utilize a transcriptional mechanism to increase $o b$ mRNA, with subsequent increases in leptin protein production. Continued elucidation of the molecular components involved in secretion of leptin should provide a more-comprehensive understanding of the vesicle transport and secretory pathways in adipocytes.

\section{ACKNOWLEDGMENTS}

This work was supported by National Institutes of Health grants R01 DK-51668 (B.C.) and National Research Service Award DK-09745 (R.L.B.).

\section{REFERENCES}

Auwerx, J., and Staels, B. (1998). Lancet 351, 737-742.

Barr, V.A., Malide, D., Zarnowski, M.J., Taylor, S.I, and Cushman, S.W. (1997). Endocrinology 138, 4463-4472.

Baumann, H., Morella, K.K., White, D.W., Dembski, M., Bailon, P.S., Kim, H., Lai, C.F., and Tartaglia, L.A. (1996). Proc. Natl. Acad. Sci. U.S.A. 93, 8374-8378.

Bcnoist, F., Paulina, L., McDonncl, M., Doclle, Il., Milnc, R., and McPhcrson, R. (1998). J. Biol. Chem. 272, 23572-23577.

Birnbaum, M.J. (1992). Intl. Rev. Cytol. 137, 239-297

Bjorbaek, C., Elmquist, J.K., Frantz, J.D., Shoelson, S.E., and Flier, J.S. (1998). Mol Cell 1, 619-625.

Bogan, J.S., and Lodish, H.F. (1999). J. Cell Biol. 146, 609-620.

Bradley, R.L., and Cheatham, B. (1999). Diabetes 48, 272-278.

Bradley, R.L., Kokkotou, E.G., Maratos-Flier, E., and Cheatham, B. (2000). Diabetes 49, 1073-1077.

Brooks, C.C., Scherer, P.E., Cleveland, K., Whittemore, J.L., Lodish, H.F., and Cheatham, B. (2000). J. Biol. Chem. 275, 2029-2036.

Calakos, N., and Scheller, R.H. (1994). J. Biol. Chem. 269, 24534-24537.

Caro, J.F., Sinha, M.K., Kolaczynski, J.W., Zhang, P.L., and Considine, R.V. (1996). Diabetes 45, 1455-1462.

Casanueva, F.F., and Dieguez, C. (1999). Front. Neuroendocrinol. 20, 317-363.

Castell, J.V., Gomez-Lechon, M.J., David, M., Andus, T., Geiger, T., Trullenque, R., Fabra, R., and Heinrich, P.C. (1989). FEBS Lett. 242, 237-239.

Chambers, J., Ames, R.S., Bergsma, D., Muir, A., Fitzgerald, L.R., Hervieu, G., Dytko, G.M., Foley, J.J., Martin, J., Liu, W.S., Park, J., Ellis, C., Ganguly, S., Konchar, S., Cluderay, J., Leslie, R., Wilson, S., and Sarau, H.M. (1999). Nature 400, 261-265.

Cheatham, B., and Kahn, C.R. (1995). Endocr. Rev. 16, 117-142. 
Cheatham, B., Volchuk, A., Kahn, C.R., Wang, L., Rhodes, C.J., and Klip, A. (1996). Proc. Natl. Acad. Sci. U.S.A. 93, 15169-15173.

Ciantlone, K.M., Sniderman, A.D., Dallongeville, J., Bertrand, M., Raffai, E., and Davignon, J. (1992). Clin. Invest. Med. 15, 132-140.

Claffey, K., Wilkison, W., and Spiegelman, B. (1992). J. Biol. Chem. 267, 16317-16322.

Clement, K., Vaisse, C., Lahlou, N., Cabrol, S., Pelloux, V., Cassuto, D., Gourmelen, M., Dina, C., Chambaz, J., Lacorte, J.M., Basdevant, A., Bougneres, P., leBouc, Y., Froguel, P., and GuyGrand, B. (1998). Nature 392, 398-401.

Cohen, B., Novick, D., and Rubinstein, M. (1996). Science 274, 1185-1188.

Deng, C., Moinat, M., Curtis, L., Nadakal, A., Preitner, F., Boss, O., Assimacopoulos-Jeannet, F., Seydoux, J., and Giacobino, J.P. (1997). Endocrinology 138, 548-552.

De Vos, P., Saladin, R., Auwerx, J., and Staels, B. (1995). J. Biol. Chem. 270, 15958-15961.

Dobson, D., Kambe, A., Block, E., Dion, T., Lu, H., Castellot, J., and Spiegelman, B. (1990). Cell 61, 223-230.

Elferink, L.A., and Scheller, R.H. (1995). Prog. Brain Res. 105, 79-85.

Elmquist, J.K., Maratos-Flier, E., Saper, C.B., and Flier, J.S. (1998). Nat. Neurosci. 1, 445-450.

Emilsson, V., Liu, Y.L., Cawthorne, M.A., Morton, N.M., and Davenport, M. (1997). Diabetes 46, 313-316.

Frederich, R.C., Lollmann, B., Hamann, A., Napolitano-Rosen, A., Kahn, B.B., Lowell, B.B., and Flier, J.S. (1995). J. Clin. Invest. 96, 1658-1663.

Funahashi, T., Nakamura, T., Shimomura, I., Macda, K., Kuriyama, H., Takahashi, M., Arita, Y., Kihara, S., and Matsuzawa, Y. (1999). Intern. Med. 38, 202-206.

Gettys, T.W., Harkness, P.J., and Watson, P.M. (1996). Endocrinology 137, 4054-4057.

Ghilardi, N., Ziegler, S., Wiestner, A., Stoffel, R., Heim, M.H., and Skoda, R.C. (1996). Proc. Natl. Acad. Sci. U.S.A. 93, 6231-6235.

Grunfeld, C., and Feingold, K.R. (1991). Biotherapy 3, 143-158.

Gualillo, O., Lago, F., Garcia, M., Menendez, C., Senaris, R., Casanueva, F.F., and Dieguez, C. (1999). Endocrinology 140, 5149-5153.

Haass, N.K., Kartenbeck, J., and Leube, R.E. (1996). J. Cell Biol. 134, 731-746.

Halleux, C.M., Servais, 1., Reul, B.A., Detry, R., and Brichard, S.M. (1998). J. Clin. Endocrinol. Metab. 83, 902-910.

Hardie, L.J., Guilhot, N., and Trayhurn, P. (1996). Horm. Metab. Res. 28, 685-689.

Hay, J.C., and Scheller, R.H. (1997). Curr. Opin. Cell Biol. 9, 505-512.

Kieffer, T.J., Heller, R.S., and Habener, J.F. (1996). Biochem. Biophys. Res. Commun. 224, 522-527.

Kieffer, T.J., Heller, R.S., Leech, C.A., Holz, G.G., and Habener, J.F. (1997). Diabetes 46, 1087-1093.

Kroder, G., Kellerer, M., and Haring, H.U. (1996). Exp. Clin. Endocrinol. Diabetes 104(suppl. 2), 66 (abstr.).

Larsson, H., and Ahren, B. (1996). J. Clin. Endocrinol. Metab, 81, 4428-4432.

Lee, G.H., Proenca, R., Montez, J.M., Carroll, K.M., Darvishzadeh, J.G., Lee, J.l., and Friedman, J.M. (1996). Nature 379, 632-635.

Matlin, K., and Simons, K. (1983). Cell 34, 233-243.

Mercer, J.G., Hoggard, N., Williams, L.M., Lawrence, C.B., Hannah, L.T., and Trayhurn, P. (1996). FEBS Lett. 387, 113-116.

Min, J., Okada, S., Kanzaki, M., Elmendorf, J.S., Coker, K.J., Ceresa, B.P., Syu, L.J., Noda, Y., Saltiel, A.R., and Pessin, J.E. (1999). Mol. Cell 3, 751-760.

Mohamed-Ali, V., Pinkney, J.H., and Coppack, S.W. (1998). Int. J. Obes. Relat. Metab. Disord. 22 , 1145-1158

Moinat, M., Deng, C., Muzzin, P., Assimacopoulos-Jeannet, F., Seydoux, J., Dulloo, A.G., and Giacobino, J.P. (1995). FEBS Lett. 373, 131-134. 
Montague, C.T., Farooqi, I.S., Whitehead, J.P., Soos, M.S., Rau, H., Wareham, N.J., Sewter, C.P., Digby, J.E., Mohammed, S.N., Hurst, J.A., Cheetham, C.H., Early, A.R., Barnett, A.H., Prins, J.B., and O'Rahilly, S. (1997). Nature 387, 903-908.

Muller, G., Ertl, J., Gerl, M., and Preibisch, G. (1997). J. Biol. Chem. 272, 10585-10593.

Murakami, T., Iida, M., and Shima, K. (1995). Biochem. Biophys. Res. Commun. 214, 1260-1267.

Ouchi, N., Kihara, S., Arita, Y., Maeda, K., Kuriyama, H., Okamoto, Y., Hotta, K., Nishida, M., Takahashi, M., Nakamura, T., Yamashita, S., Funahashi, T., and Matsuzawa, Y. (1999). Circulation 100, 2473-2476.

Papaspyrou-Rao, S., Schneider, S.H., Petersen, R.N., and Fried, S.K. (1997). J. Clin. Endocrinol. Metab. 82, 1635-1637.

Pessin, J.E., Thurmond, D.C., Elmendorf, J.S., Coker, K.J., and Okada, S. (1999). J. Biol. Chem. 274, 2593-2596.

Pfeffer, S.R. (1999). Nat. Cell Biol. 1, E17-E22

Prins, J.B., Niesler, C.U., Winterford, C.M., Bright, N.A., Siddle, K., O'Rahilly, S., Walker, N.I., and Cameron, D.P. (1997). Diabetes 46, 1939-1944.

Qu, D., Ludwig, D.S., Gammeltoft, S., Piper, M., Pelleymounter, M.A., Cullen, M.J., Mathes, W.F., Przypek, J., Kanarek, R., and Maratos-Flier, E. (1996). Nature 380, 243-247.

Ravussin, E., Pratley, R.E., Maffei, M., Wong, H., Friedman, J.M., Bennett, P.H., and Bogardus, C. (1997). Nature Med. 3, 238-240.

Rentsch, J., and Chiesi, M. (1996). FEBS Lett. 379, 55-59.

Rice, A.M., Fain, J.N., and Rivkees, S.A. (2000). Endocrinology 141, 1442-1445

Rice, L.M., and Brunger, A.T. (1999). Mol. Cell 4, 85-95.

Saito, Y., Nothacker, H.P., Wang, Z., Lin, S.H., Leslie, F., and Civelli, O. (1999). Nature 400, 265-269.

Saladin, R., De Vos, P., Guerre-Millo, M., Leturque, A., Girard, J., Staels, B., and Auwerx, J. (1995). Nature 377, 527-529.

Scherer, P., Williams, S., Fogliano, M., Baldini, G., and Lodish, H.F. (1995). J. Biol. Chem. 270, 26746-26749.

Spooner, P., Chernick, S., Garrison, M., and Scow, R. (1979). J. Biol. Chem. 254, $10021-10029$.

St-Denis, J.F., and Cushman, S.W. (1998). J. Basic. Clin. Physiol. Pharmacol. 9, 153-165.

Strobel, A., Issad, T., Camoin, L., Ozata, M., and Strosberg, A.D. (1998). Nature Genet. 18, 213-215.

Tamori, Y., Kawanishi, M., Niki, T., Shinoda, H., Araki, S., Okazawa, H., and Kasuga, M. (1998). J. Biol. Chem. 273, 19740-19746.

Tartaglia, L.A., Dembski, M., Weng, X., Deng, N., Culpepper, J., Devos, R, Richards, G.J., Campfield, L.A., Clark, F.T., Deeds, J., Muir, C., Sanker, S., Moriarty, A., Moore, K.J., Smutko, J.S., Mays, G.G., Woolf, E.A., Monroe, C.A., and Tepper, R.I. (1995). Cell 83, 1263-1271.

Tellam, J.T., Macaulay, S.L., McIntosh, S., Hewish, D.R., Ward, C.W., and James, D.E. (1997). J. Biol. Chem. 272, 6179-6186.

Thiele, C., Hannah, M.J., Fahrenholz, F., and Huttner, W.B. (2000). Nature Cell Biol. 2, 42-49.

Trayhurn, P., Hoggard, N., Mercer, J.G., and Rayner, D.V. (1999). Int. J. Obes. Relat. Metab. Disord. 23(suppl. 1), 22-28.

Vaisse, C., Halaas, J.L., Horvath, C.M., Darnell, J.E., Jr., Stoffel, M., and Friedman, J.M. (1996). Nature Genet. 14, 95-97.

Weber, T., Zemelman, B.V., McNew, J.A., Westermann, B., Gmachl, M., Parlati, F., Sollner, T.H., and Rothman, J.E. (1998). Cell 92, 759-772.

Wei, S., Lai, K., Patel, S., Piantedosi, R., Shen, H., Colantuoni, V., Kraemer, F., and Blaner, W. (1997). J. Biol. Chem. 272, 14159-14165.

Weigle, D. (1997). Ann. Endocrinol. Paris 58, 132-136.

Zhang, Y., Proenca, R., Maffei, M., Barone, M., Leopold, L., and Friedman, J. (1994). Nature 372, 425-432. 